\title{
Co-Delivery of Docetaxel and Salinomycin to Target Both Breast Cancer Cells and Stem Cells by PLGA/TPGS Nanoparticles
}

This article was published in the following Dove Press journal: International Journal of Nanomedicine

Jie $\mathrm{Gao}^{1,2, *}$

Junjie Liu (D) ${ }^{1,3, *}$

Fangyuan $\mathrm{Xie}^{4, *}$

Ying $\mathrm{Lu}^{3}$

Chuan Yin $^{5}$

Xian Shen'

'Department of Gastrointestinal Surgery, The Second Affiliated Hospital and Yuying Children's Hospital of Wenzhou Medical University, Zhejiang, People's Republic of China; ${ }^{2}$ Scientific Research Center, The Second Affiliated Hospital and Yuying Children's Hospital of Wenzhou Medical University, Zhejiang, People's Republic of China; ${ }^{3}$ Department of Pharmaceutical Sciences, Second Military Medical University, Shanghai, People's Republic of China; ${ }^{4}$ Department of Pharmacy, Shanghai Eastern Hepatobiliary Surgery Hospital, Shanghai, People's Republic of China; ${ }^{5}$ Department of Gastroenterology, Changzheng Hospital, Second Military Medical University, Shanghai, People's Republic of China

*These authors contributed equally to this work
Purpose: Conventional chemotherapy is hampered by the presence of breast cancer stem cells (BCSCs). It is crucial to eradicating both the bulky breast cancer cells and BCSCs, using a combination of conventional chemotherapy and anti-CSCs drugs. However, the synergistic ratio of drug combinations cannot be easily maintained in vivo. In our previous studies, we demonstrated that the simultaneous delivery of two drugs via nanoliposomes could maintain the synergistic drug ratio for $12 \mathrm{~h}$ in vivo. However, nanoliposomes have the disadvantage of quick drug release, which makes it difficult to maintain the synergistic drug ratio for a long time. Herein, we developed a co-delivery system for docetaxel (DTX) - a first-line chemotherapy drug for breast cancer - and salinomycin (SAL) - an anti-BCSCs drug - in rigid nanoparticles constituted of polylactide-co-glycolide/D-alpha-tocopherol polyethylene glycol 1000 succinate (PLGA/TPGS).

Methods: Nanoparticles loaded with SAL and DTX at the optimized ratio (NSD) were prepared by the nanoprecipitation method. The characterization, cellular uptake, and cytotoxicity of nanoparticles were investigated in vitro, and the pharmacokinetics, tissue distribution, antitumor and anti-CSCs activity of nanoparticles were evaluated in vivo.

Results: We demonstrated that a SAL/DTX molar ratio of 1:1 was synergistic in MCF-7 cells and MCF-7-MS. Moreover, the enhanced internalization of nanoparticles was observed in MCF-7 cells and MCF-7-MS. Furthermore, the cytotoxicity of NSD against both MCF-7 cells and MCF-7-MS was stronger than the cytotoxicity of any single treatment in vitro. Significantly, NSD could prolong the circulation time and maintain the synergistic ratio of SAL to DTX in vivo for $24 \mathrm{~h}$, thus exhibiting superior tumor targeting and anti-tumor activity compared to other treatments.

Conclusion: Co-encapsulation of SAL and DTX in PLGA/TPGS nanoparticles could maintain the synergistic ratio of drugs in vivo in a better manner; thus, providing a promising strategy for synergistic inhibition of breast cancer.

Keywords: combined therapy, breast cancer stem cells, docetaxel, salinomycin, nanoparticles

\section{Introduction}

Breast cancer is one of the most common cancers in women and accounts for $30 \%$ of all cancer diagnoses. ${ }^{1}$ Although great advances have been achieved in the treatment of breast cancer, it is still the second leading cause of cancer-related deaths in women. Conventional chemotherapy drugs can effectively kill the bulky breast cancer cells, but breast cancer stem cells (BCSCs) in tumor tissues are resistant to these chemotherapy drugs. Moreover, several reports have demonstrated
Correspondence: Jie Gao; Xian Shen Department of Gastrointestinal Surgery, The Second Affiliated Hospital and Yuyin University, 109 Xueyuan W Road, Lucheng, Wenzhou, Zhejiang 325000 People's Republic of China

Tel +86-0577-888I638I; 86-057788002709

Fax +86-0577-888I638I

Email gaojiehighclea@I63.com;

shenxian1963@sina.com
International Journal of Nanomedicine 2019:14 9199-9216

9199

DovePress $f$ in $\boldsymbol{v}$

http://doi.org/10.2147यIN.S230376 
that non-CSCs can be converted to CSCs spontaneously and stochastically. ${ }^{2-5}$ Thus, it is necessary to eradicate both bulky breast cancer cells and BCSCs to achieve better therapeutic efficacy in breast cancer. Similarly, in our previous study, we have shown that combined therapy to target both liver cancer cells and CSCs could increase the therapeutic efficacy in liver cancer. ${ }^{6}$

The isolation and identification of BCSCs are critical for the targeted therapy of BCSCs. It is believed that CD44 $+\mathrm{CD} 24-/$ low phenotype cells in breast cancer are BCSCs. For the first time, the tumorigenic cells with CD44 + CD24-/low lineage were identified and isolated in eight out of nine patients by Al-Hajj et $\mathrm{al}^{7}$. However, the isolation of CSCs using cellular biomarkers has several limitations. ${ }^{8}$ Firstly, cellular biomarkers may be damaged by enzymes, which digest tumor tissues. Secondly, the survival rate of the isolated cells from flow cytometry is low. The spheroid colony formation is considered an effective way to isolate CSCs. Ponti et al and our previous studies have successfully isolated BCSCs with CD44 + CD24 phenotype from MCF-7 breast cancer cell lines by the spheroid colony formation, and MCF-7 mammospheres (MCF-7-MS) was found to exhibit enhanced tumorigenesis compared to MCF-7 cells. ${ }^{9,10}$

The common strategy for targeting both cancer cells and CSCs is the cocktail strategy, in which chemotherapy drugs and anti-CSCs drugs are physically mixed and then administered. However, these strategies have two obvious disadvantages. Firstly, the interaction between these two drugs (synergistic, additive, or antagonistic effects) has not been evaluated and optimized in these studies. ${ }^{11,12}$ Secondly, the pharmacokinetics, tissue distribution, and cell membrane penetration ability of different drugs are diverse. Therefore, the ratio of drugs will be uncontrollable after they enter the body and drug uptake at the tumor site is inconsistent. Therefore, the strategy for targeting both cancer cells and CSCs needs to be improved by delivering synergistic ratios of chemotherapy drugs and anti-CSCs drugs to cancer cells.

Nanomedicines are new nano-drug delivery systems, which provide a new solution to the problem of a drug combination strategy. Compared to common drugs, nanomedicines have the following advantages: they increase the bioavailability of insoluble drugs, they prolong drug circulation time in vivo, and they improve drug efficacy and reduce side effects. ${ }^{13-15}$ It is noteworthy that nanomedicines can deliver both drugs to the tumor at the same time, which synchronizes the treatment of tumors with time and space. ${ }^{16}$ Moreover, the pharmacokinetics and distribution of nanomedicines in vivo depend on the nanocarriers, and are not associated with the properties of drugs. Therefore, nanomedicines represent a robust tool to deliver synergistic ratios of drugs to tumors. ${ }^{17,18}$

In our previous studies, we successfully used nanoliposomes to deliver synergistic ratio of doxorubicin and SAL to liver cancer cells, resulting in superior therapeutic efficacy towards liver cancer compared to single-drug treatment with doxorubicin and SAL. However, nanoliposomes have severe disadvantages of quick drug release $(\sim 80 \%$ drug release during the first $12 \mathrm{~h}$ ), and our results showed that nanoliposomes could maintain synergistic drug ratio only for $12 \mathrm{~h}$ in vivo. ${ }^{6}$ In contrast, poly lactic-co-glycolic acid (PLGA) nanoparticles have a more rigid structure and show significantly slowed drug release from several days to several weeks. Further, PLGA nanoparticles possess good biocompatibility, and the polymer PLGA has been approved by US food and drug administration (FDA) for clinic use. ${ }^{19-23}$ Furthermore, various strategies such as surface modification, newly synthesized and porous have been developed to improve PLGA nanoparticles. ${ }^{24-26} \mathrm{D}-\alpha-$ Tocopheryl polyethylene glycol 1000 succinate (TPGS), a water-soluble derivative of natural vitamin $\mathrm{E}$, has been approved by FDA as a safe pharmaceutical excipient, which can be used as emulsifier, solvent, and stabilizer in pharmaceutical preparations. ${ }^{27-29}$ If TPGS is added to PLGA nanoparticles, it cannot only play a pore-forming agent role that may result in smaller particle size, higher drug encapsulation efficiency, and faster drug release but also play bioactive agent role that can inhibit P-glycoprotein to enhance the therapeutic effects of drugs in cancer. Zhu et al have used PLGA/TPGS nanoparticles to deliver DTX for enhanced chemotherapy against multi-drug resistant breast cancer. ${ }^{30}$

In this study, the combination of docetaxel (DTX), a first-line chemotherapy drug for breast cancer, and salinomycin (SAL), which could selectively inhibit BCSCs was used to target both bulky breast cancer cells and BCSCs. BCSCs were isolated and enriched by serumfree suspension culture. The synergistic ratio of SAL and DTX in breast cancer cells and BCSCs were investigated using median-effect analysis. Then, PLGA/TPGS nanoparticles were used to maintain the synergistic combination of DTX and SAL to target both breast cancer cells and BCSCs. The cellular uptake and cytotoxicity of nanoparticles were evaluated in vitro, and the pharmacokinetics, tissue distribution, and anti-tumor and BCSCs activity of 
nanoparticles were determined in vivo. Our results showed that NSD could prolong the circulation time and maintain the synergistic ratio of SAL to DTX for $24 \mathrm{~h}$ in vivo, exhibiting better tumor targeting, and better anti-tumor and CSCs activity than other treatments.

\section{Materials and Methods Materials, Cell Culture, and Mice}

DTX was obtained from ShangHai Biochempartner Co., Ltd. (Shanghai, China). SAL, Coumarin-6, PLGA (50:50, MW 24,000-38,000 Da), TPGS, epidermal growth factor (EGF), basic fibroblast growth factor (bFGF), and insulintransferrin-selenium (ITS) were purchased from SigmaAldrich (MO, USA). Dulbecco's modified Eagle's medium (DMEM) with high glucose, DMEM-F12, penicillin streptomycin, and phosphate-buffered saline were obtained from Thermo Scientific Hyclone (IL, USA). Fetal bovine serum (FBS), B27, StemPro Accutase Cell Dissociation Reagent, and trypsin-ethylenediaminetetraacetic acid solution were purchased from Invitrogen (CA, USA). The Cell Counting Kit 8 (CCK-8) was provided by Dojindo Laboratories (Kumamoto, Japan). DiR was obtained from Biotium (CA, USA). 4',6-Diamidino-2-phenylindole (DAPI) was purchased from Beyotime Biotechnology (Shanghai, China).

The MCF-7 breast cancer cells were purchased from the Cell Culture Center of the Shanghai Institutes for Biological Sciences of the Chinese Academy of Sciences (Shanghai, China) and cultured in DMEM medium with $10 \% \mathrm{FBS}, 100 \mathrm{U} / \mathrm{mL}$ penicillin and $100 \mu \mathrm{g} / \mathrm{mL}$ streptomycin. To obtain MCF-7 mammospheres (MCF-7-MS), MCF-7 cells were plated at $1 \times 10^{4}$ cells $/ \mathrm{mL}$ in serumfree DMEM-F12, supplemented with $1 \times$ B27, $20 \mathrm{ng} / \mathrm{mL}$ EGF, $20 \mathrm{ng} / \mathrm{mL}$ bFGF, and $1 \times$ ITS. Mammospheres were enzymatically dissociated once a week by incubating in StemPro Accutase Cell Dissociation Reagent for $10 \mathrm{~min}$ at $37^{\circ} \mathrm{C}$ and plated at $1 \times 10^{4}$ cells $/ \mathrm{mL}$. Before the experiment, all cells were passed through a $100-\mu \mathrm{m}$ sieve (Becton Dickinson).

Sprague-Dawley (SD) rats (male, $200 \pm 20 \mathrm{~g}$ ) and $\mathrm{BALB} / \mathrm{c}$ nude mice (female, 5 weeks, about $20 \mathrm{~g}$ ) were purchased from Shanghai Experimental Animal Center of Chinese Academic of Sciences (Shanghai, China). All animal procedures were approved by the Committee on Animals of the Second Military Medical University. All animal procedures were performed in accordance with the guidelines of the Committee on Animal of the Second
Military Medical University. Before use in experiments, the mice were allowed to acclimatize for a week.

\section{Median-Effect Analysis of Drug Combinations}

The cytotoxic effects of SAL and DTX against MCF-7-MS and MCF-7 cells were measured by CCK-8. Briefly, the cells were seeded at a density of $5 \times 10^{3}$ cells/well in 96-well plates and incubated overnight. Then, the cells were incubated with a series of varying concentrations of SAL/DTX for $48 \mathrm{~h}$. The fixed molar ratios of SAL and DTX (9:1, 6:1, $3: 1,2: 1,1: 1,1: 2,1: 3,1: 6,1: 9)$ were used for the combined study. Subsequently, $10 \mu \mathrm{L}$ CCK- 8 solution was added to each well and incubated for an additional $2 \mathrm{~h}$, the absorbance of each well was measured by a Multiskan MK3 Microplate Reader (Thermo Scientific, USA) at $450 \mathrm{~nm}$. Cell viability was calculated by the following formula: ([AE - AB]/[AC $\mathrm{AB}]) \times 100 \%$. AE, AC, and $\mathrm{AB}$ were defined as the absorbance of experimental samples, untreated samples, and blank controls, respectively. The optimal synergistic molar ratio of SAL and DTX was calculated with the median-effect analysis by the CompuSyn software (Biosoft, Cambridge, UK). The occurrence of ratio-dependent synergy was determined by plotting the combination index $(\mathrm{CI})(\mathrm{CI}<1$, synergy; CI $\sim$, additivity; and CI $>1$, antagonism) versus the fraction of cells affected $(\mathrm{Fa})$.

\section{Preparation of Nanoparticles}

The nanoprecipitation method was employed to generate nanoparticles as described previously. ${ }^{31}$ Briefly, $90 \mathrm{mg}$ PLGA/TPGS mixture (with 20\% TPGS percentage) was dissolved in $8 \mathrm{~mL}$ acetone and injected into $0.06 \%(\mathrm{w} / \mathrm{v})$ TPGS aqueous solution under stirring overnight to completely volatilize acetone. Then, the nanoparticles were centrifuged and washed to remove excess TPGS and free drugs. The nanoparticles were suspended and freeze-dried for $48 \mathrm{~h}$ to generate nanoparticle powders. The nanoparticle powders were then dispersed into PBS before use. For the preparation of drug-loaded nanoparticles, the drug was dissolved along with PLGA/TPGS mixture and the fabrication process was exactly as described above. The following definitions were used: blank nanoparticles, NP; SAL-loaded nanoparticles, NS; DTX-loaded nanoparticles, ND; nanoparticles co-delivering SAL and DTX, NSD Coumarin-6-loaded nanoparticles, NC; and DiR-loaded nanoparticles, NDiR. 


\section{Characterization of Nanoparticles}

The particle size and zeta potential of nanoparticles were investigated by dynamic light scattering using a Zetasizer Nano S (Malvern Instruments, UK). The morphology of nanoparticles was observed by transmission electron microscopy (TEM). Briefly, the nanoparticles were dropped onto a carbon-coated copper grid and dyed with $2 \%$ phosphotungstic acid solution for 5 mins. After airdrying, the samples were imaged using the Hitachi H-600 TEM (accelerating voltage of $200 \mathrm{kV}$ ). The drug loading and encapsulation efficacy (EE) of SAL and DTX in nanoparticles were determined by HPLC (L-2000, Hitachi, Japan) as described previously. The nanoparticle powders were fully dissolved in $1 \mathrm{~mL}$ of methanol to obtain a clear solution sample for analysis.

To investigate the in vitro drug release profile of NSD. Nanoparticle solution $(5 \mathrm{~mL})$ was transferred into a dialysis membrane (MWCO 10kDa, Spectra/Por ${ }^{\circledR}$ ), which was soaked into a vial containing PBS (40 mL; pH 7.4 or 5.0) and incubated in a water bath at $37^{\circ} \mathrm{C}$ with gentle shaking (100 rpm). At predetermined time intervals $(1,2,4,6,8,12$, $16,24,48,72,96,120$ and $240 \mathrm{~h}$ ), a $1 \mathrm{~mL}$ aliquot of release buffer was taken and replaced with $1 \mathrm{~mL}$ of fresh PBS $(\mathrm{pH}$ 7.4 or 5.0). The amount of SAL and DTX in the release buffer was determined as described before. The release rate was calculated by the following formula: (Wn/Wtotal) $\times$ $100 \%$. Wn was defined as the amount of accumulative released SAL or DTX, and Wtotal was defined as the total amount of SAL or DTX.

\section{In vitro Cellular Uptake}

The cellular uptake of nanoparticles in MCF-7 cells or MCF-7-MS was examined by confocal laser scanning microscopy (CLSM, TCS-SP5, Leica, Germany). MCF-7 cells or MCF-7-MS were trypsinized and seeded on glassbottom dishes overnight. Then, the cells were treated with free coumarin- 6 or $\mathrm{NC}$ which had an equivalent concentration of coumarin-6 $(1 \mu \mathrm{g} / \mathrm{mL})$ for $1 \mathrm{~h}$ at $37^{\circ} \mathrm{C}$. After incubation, the cells were washed with PBS three times and fixed with $4 \%$ paraformaldehyde for $10 \mathrm{~min}$. Thereafter, the cells were stained with DAPI for $10 \mathrm{~min}$ and washed three times. Finally, the immunofluorescence of cells was observed by CLSM.

\section{In vitro Cytotoxicity}

The cytotoxic effects of nanoparticles against MCF-7 cells or MCF-7-MS were evaluated by a CCK- 8 assay as mentioned above. Briefly, the cells were seeded at a density of $5 \times 10^{3}$ cells/well in 96-well plates and incubated overnight. Then, the medium was replaced with fresh medium containing varying concentrations of SAL, DTX, SAL + DTX, NP, NS, ND, NS + ND, or NSD and incubated for $48 \mathrm{~h}$. Next, a $10 \mu \mathrm{L}$ CCK- 8 solution was added to each well to evaluate cytotoxicity. After incubation for about $2 \mathrm{~h}$, the absorbance of each well was measured at $450 \mathrm{~nm}$.

\section{Pharmacokinetics}

Fifteen SD rats (male, $200 \pm 20 \mathrm{~g}$ ) were randomly assigned to three groups (five rats per group). The rats were intravenously administered with SAL + DTX, NS + ND and NSD, equivalent to $2 \mathrm{mg} / \mathrm{kg}$ and $2.1 \mathrm{mg} / \mathrm{kg}$ of $\mathrm{SAL}$ and DTX respectively. At different time points, $500 \mu \mathrm{L}$ of blood samples were collected from the fossa orbitalis vein into heparinized centrifuge tubes and immediately centrifuged at $12,000 \mathrm{rpm}$ for $10 \mathrm{~min}$ to collect the plasma fraction. All plasma samples were pre-treated as previously described: For SAL, $50 \mu \mathrm{L}$ of plasma was mixed with $90 \mu \mathrm{L}$ of internal standard (fenofibrate, $1 \mu \mathrm{g} / \mathrm{mL}$ ) and $10 \mu \mathrm{L}$ of acetonitrile. After vortexing for $1 \mathrm{~min}$, the sample was centrifuged at $12,000 \mathrm{rpm}$ for $10 \mathrm{~min}$, and $100 \mu \mathrm{L}$ of the supernatant was separated for LC/MS analysis. Plasma concentrations of SAL were determined using an Agilent Technologies 1200 series LC/MS system (Agilent, USA) equipped with a Symmetry C18 column $(3.0 \times 100 \mathrm{~mm}, 3.5 \mu \mathrm{m}$, waters, USA). The mobile phase was composed of $90: 10(\mathrm{v} / \mathrm{v}) \mathrm{A} / \mathrm{B}$, where $\mathrm{A}$ was acetonitrile, B was $2 \%(\mathrm{v} / \mathrm{v})$ acetic acid in water containing $2 \mathrm{mM}$ ammonium acetate, and the flow rate was $0.4 \mathrm{~mL} / \mathrm{min}$. Quantification was performed using SIM positive mode with SAL ion $\mathrm{m} / \mathrm{z} 773.4 \quad[\mathrm{M}+\mathrm{H}]+$ and fenofibrate $\mathrm{m} / \mathrm{z} 361.1[\mathrm{M}+\mathrm{H}]+$. The optimal mass parameters were as follows: Fragmentor, $70 \mathrm{eV}$; Dying Gas Flow Rate, 8 L/min; Nebulizer Pressure, 45 psig; Drying Gas Temperature, $350^{\circ} \mathrm{C}$. For DTX, $100 \mu \mathrm{L}$ of plasma was mixed with $25 \mu \mathrm{L}$ of internal standard (paclitaxel, $1 \mu \mathrm{g} / \mathrm{mL}$ in methanol), vortexed for $1 \mathrm{~min}$, and extracted by methyl tertiary-butyl ether. After vortexing for $1 \mathrm{~min}$, the sample was centrifuged at $12,000 \mathrm{rpm}$ for $10 \mathrm{~min}$, and $450 \mu \mathrm{L}$ of the supernatant was collected and evaporated under nitrogen flow at $40^{\circ} \mathrm{C}$, the residual was dissolved in $50 \mu \mathrm{L}$ methanol for LC/MS analysis. Plasma concentrations of SAL were determined using an Agilent Technologies 1200 series LC/ MS system (Agilent, USA) equipped with a Symmetry C18 column $(3.0 \times 100 \mathrm{~mm}, 3.5 \mu \mathrm{m}$, waters, USA $)$. The mobile phase was composed of 70:30 (v/v) A/B, where A was 
methanol, B was $0.1 \%(\mathrm{v} / \mathrm{v})$ formic acid in water containing $2 \mathrm{mM}$ ammonium acetate, and the flow rate was $0.3 \mathrm{~mL} / \mathrm{min}$. Quantification was performed using SIM positive mode with DTX ion $\mathrm{m} / \mathrm{z} 829.8[\mathrm{M}+\mathrm{Na}]+$ and paclitaxel $\mathrm{m} / \mathrm{z} 875.8[\mathrm{M}$ $+\mathrm{Na}]+$. The optimal mass parameters were as follows: Dying Gas Flow Rate, 10 L/min; Nebulizer Pressure, 35 psig; Drying Gas Temperature, $35^{\circ} \mathrm{C}$; Capillary Voltage, positive $4000 \mathrm{~V}$. Pharmacokinetics parameters were calculated using the DAS 2.0 software.

\section{In vivo Tissue Distribution}

For the analysis of the in vivo tissue distribution of nanoparticles, DiR was used as a fluorescence probe. BALB/c nude mice (female, 5 weeks, about $20 \mathrm{~g}$ ) were inoculated via orthotopic injection on the left side of the mammary fat pad with $1 \times 10^{6} \mathrm{MCF}-7$ cells. When the tumor volume reached $\sim 150 \mathrm{~mm}^{3}$, the mice were randomly assigned to three groups: saline, free DiR, and NDiR. All the formulations were injected via tail vein as a single dose $(10 \mu \mathrm{g}$ DiR per mouse). The mice were anesthetized with isoflurane, and in vivo fluorescence images were observed by a MAESTRO in vivo imaging system (Maestro, MA, USA) at predetermined time points $(2,4,6,8,12$, and $24 \mathrm{~h}$ ). After $24 \mathrm{~h}$, the mice were sacrificed, and tumors, as well as other organs, were excised and imaged. The fluorescence imaging conditions were as follows: in vivo exposure time $6000 \mathrm{~ms}$; in vitro exposure time $3000 \mathrm{~ms}$; scanning wavelength $700-950 \mathrm{~nm}$; excitation/emission wavelengths $745 / 810 \mathrm{~nm}$.

\section{In vivo Anti-Tumor Assays}

The therapeutic effects of the nanoparticles in vivo were performed in MCF-7 cells derived subcutaneous tumor model. BALB/c nude mice (female, 5 weeks, about $20 \mathrm{~g}$ ) were inoculated via orthotopic injection on the right side of the mammary fat pad with $1 \times 10^{6} \mathrm{MCF}-7$ cells. When the tumor volume reached $\sim 50 \mathrm{~mm}^{3}$, the mice were randomly assigned to nine groups (six mice per group): saline, SAL, DTX, SAL + DTX, NP, NS, ND, NS + ND, and NSD. At days 8, 11, 14, 17, 20 and 23, all the formulations were injected via tail vein at the doses of SAL and DTX equivalent to 2 and $2.1 \mathrm{mg} / \mathrm{kg}$, respectively, to maintain a synergistic ratio. After the sixth treatment, mice were observed for another 2 weeks. Tumors were measured using a caliper and mice were weighed every 3 days. The tumor volume (V) was calculated using the following formula: $\mathrm{V}=(\mathrm{L} \times \mathrm{W} 2) / 2$ (L: length; W: width). The body decrease rate $(\mathrm{BDR})$ was calculated using the following formula: $\mathrm{BDR}=[(\mathrm{Wf}-\mathrm{Wi}) / \mathrm{Wf}] \times 100 \%$. Wi and $\mathrm{Wf}$ were defined as the initial body weight before treatment and final body weight after treatment, respectively. On day 37, mice were euthanized, and excised tumors were weighted. The tumor inhibitory rate (TIR) was calculated using the following formula: TIR $=[(\mathrm{Wc}-\mathrm{We}) / \mathrm{Wc}] \times$ $100 \%$. Wc and We were defined as the tumor weight of the control group and experiment groups, respectively.

\section{in vivo Anti-CSCs Activity}

The tumors were excised for CSCs examination. The ability of MCF-7 tumor cells to form tumorspheres was used to evaluate the effect of drugs on the proportion of BCSCs in vivo. Briefly, after sterilizing by $75 \%$ ethanol for 5 mins and washing with PBS, the excised tumors were cut into small pieces with a volume of about $1 \mathrm{~mm}^{3}$, and digested with collagenase I solution $(1 \mathrm{mg} / \mathrm{mL})$ at $37^{\circ} \mathrm{C}$ for $15 \mathrm{~min}$, shaking every $5 \mathrm{mins}$. After then, the cells were filtered through a $40 \mu \mathrm{m}$ cell strainer and washed with PBS. The cells were then resuspended in DMEM with $10 \% \mathrm{FBS}$ and incubated overnight at $37^{\circ} \mathrm{C}$. After adherence, the cells were trypsinized and resuspended in serumfree medium and seeded in 12-well plate with a density of 1000 cells/well. After 7 days, the formation of mammospheres in each group was statistically analyzed and photographed.

\section{Statistical Analysis}

Data in this study were analyzed using SPSS 13.0 software (SPSS, Inc., IL, USA). Student's unpaired $t$-test and oneway analysis of variance with Dunnett's or Newman Keul's post-tests were used. Differences with $\mathrm{p}$ values of less than 0.05 indicated significance. $* \mathrm{P}<0.05$; $* * \mathrm{P}<0.01$; $* * * \mathrm{P}<$ 0.001 ; n.s. represents not significant $(\mathrm{P}>0.05)$.

\section{Results}

\section{In vitro Screening of SAL and DTX for Synergy}

To screen the synergistic ratio of SAL and DTX, the median effect analysis described by Chou and Talaly was used. ${ }^{32}$ First, the cytotoxicity of SAL and DTX was evaluated in MCF-7 cells and MCF-7-MS. Both showed concentrationdependent cytotoxicity towards MCF-7 cells and MCF-7-MS (Figure 1A and B). SAL showed much enhanced cytotoxicity against MCF-7-MS compared to MCF-7 cells ( $p<0.05$ ), whereas DTX showed much enhanced cytotoxicity against MCF-7 cells compared to MCF-7-MS ( $p<0.05)$. 
A
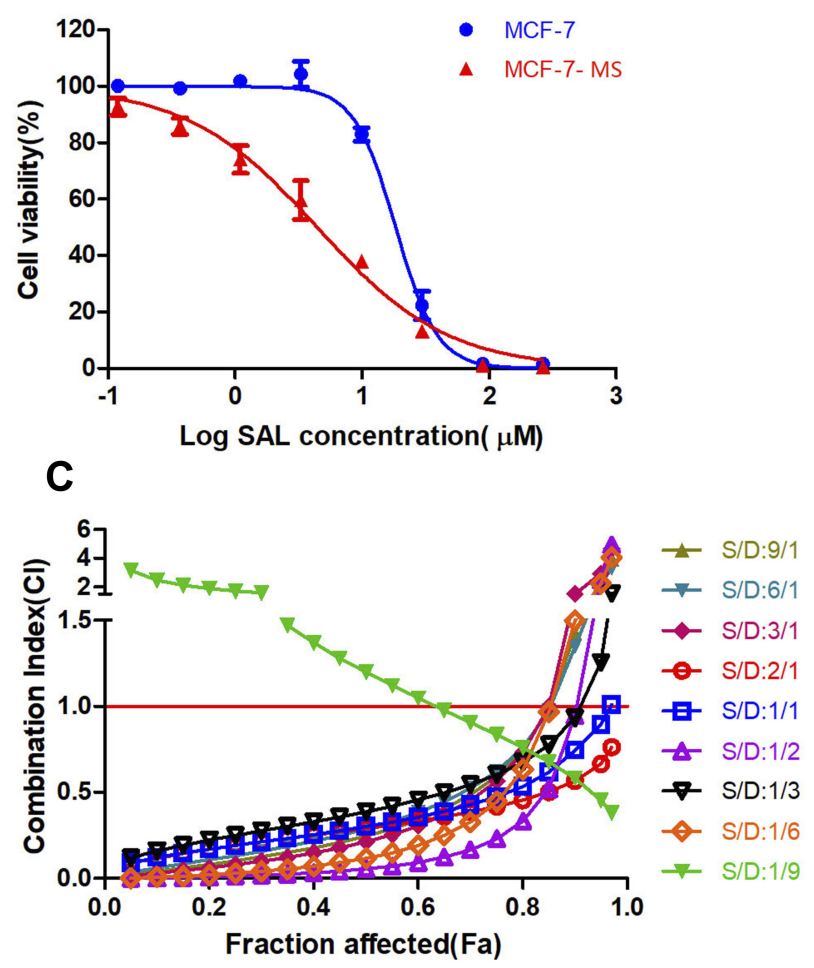

B
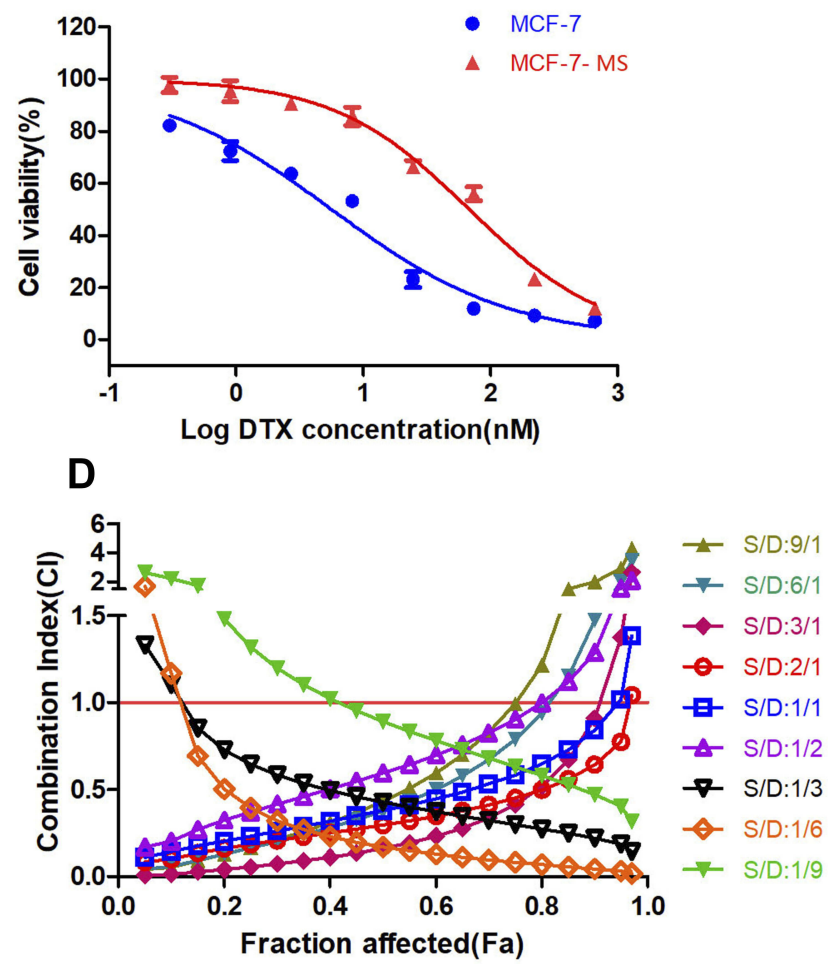

Figure I The cytotoxicity of SAL and DTX in MCF-7 cells and MCF-7-MS. The concentration-dependent cytotoxicity induced by SAL (A) and DTX (B) in MCF-7 cells and MCF-7-MS at $48 \mathrm{~h}$. In vitro screening of SAL and DTX for synergy in MCF-7 cells (C) and MCF-7-MS (D) as a function of the SAL/DTX ratio and drug concentrations. Fraction affected means the fraction of the cell that was killed. $\mathrm{Cl}$ values of $<\mathrm{I},=\mathrm{I}$, and $>\mathrm{I}$ indicate synergy, additivity, and antagonism, respectively. Data are presented as means \pm standard deviations $(n=3)$.

Subsequently, the cytotoxicity of various ratios and concentrations of SAL and DTX was determined to achieve an optimal synergistic ratio (Figure $1 \mathrm{C}$ and D, Tables 1 and 2). All selected ratios exhibited synergistic effects in most concentrations. Evidence of significant variation of $\mathrm{CI}$ as a function of drug ratio was observed, at high drug concentrations (high fa) for MCF-7 cells (Figure 1C), and at low drug concentrations (low fa) for MCF-7-MS (Figure 1D). Notably, the CI values for the SAL/DTX molar ratio of 2:1 and 1:1 were less than 1 at every drug concentrations in MCF-7 cells and at almost all concentrations in MCF-7-MS. Considering the severe side toxicity of SAL, we chose SAL/DTX molar ratio of 1:1 as the synergistic ratio for the following experiments.

\section{Characterization of Nanoparticles}

In this research, chemotherapeutic drugs SAL and DTX were successfully co-encapsulated in PLGA/TPGS nanoparticles through the nano-precipitation method. As shown in Table 3, the particle size of all nanoparticles was less than $150 \mathrm{~nm}$, with a relatively narrow polydispersity index (PDI), indicating that the nanoparticles have uniform size distribution and good dispersion. The zeta potential of all nanoparticles was about $-25 \mathrm{mV}$, which may contribute to high stability and long circulation in vivo. The EE of all nanoparticles varied from $53.28 \%$ to $84.96 \%$, with a drug loading from $4.08 \%$ to $5.48 \%$. NSD had a small size of 73.83 $\mathrm{nm}$ with a relatively narrow PDI of 0.193 , and zeta potential of $-25.7 \pm 2.03 \mathrm{mV}$ (Figure 2A and B). TEM images showed that NSD was uniform and round with a size of about $50 \mathrm{~nm}$ (Figure 2C).

The in vitro drug release profile of NSD was evaluated at pH 5.0 and 7.4 (Figure 2D and E). The release profiles were similar at $\mathrm{pH} 5.0$ and $\mathrm{pH}$ 7.4. The release of SAL and DTX could reach a plateau after 5 days. The cumulative release rates of SAL and DTX after 10 days achieved $68.19 \pm 2.13 \%$ and $65.43 \pm 1.43 \%$ respectively at $\mathrm{pH} 5.0$, and $64.28 \pm 1.21 \%$ and $60.52 \pm 1.37 \%$ respectively at $\mathrm{pH}$ 7.4. The release rate of SAL and DTX was slightly faster at $\mathrm{pH} 5.0$ than $\mathrm{pH}$ 7.4, which may be helpful in facilitating drug release in tumors. Notably, the release profiles of SAL were similar to that of DTX, and the release rates of SAL and DTX could be maintained in synergistic ratio of 1:1 in vitro. 
Table I The CI Value of the Different Molar Ratios of SAL/DTX in MCF-7 Cells

\begin{tabular}{|c|c|c|c|c|c|c|c|c|c|}
\hline \multirow[t]{2}{*}{$\mathbf{F a}$} & \multicolumn{9}{|l|}{ S/D } \\
\hline & $9 / 1$ & $6 / 1$ & $3 / 1$ & $2 / 1$ & $1 / I$ & $1 / 2$ & $1 / 3$ & $1 / 6$ & $1 / 9$ \\
\hline 0.05 & 0.024 & 0.036 & 0.016 & 0.094 & 0.090 & 0.001 & 0.120 & 0.003 & 3.155 \\
\hline 0.10 & 0.043 & $0.06 \mathrm{I}$ & 0.030 & 0.113 & 0.123 & 0.003 & 0.161 & 0.008 & 2.468 \\
\hline 0.15 & 0.062 & 0.085 & 0.046 & 0.146 & 0.148 & 0.006 & 0.194 & 0.014 & 2.119 \\
\hline 0.20 & 0.082 & 0.108 & 0.062 & 0.172 & 0.171 & 0.009 & 0.223 & 0.022 & 1.890 \\
\hline 0.25 & 0.103 & 0.133 & 0.080 & 0.194 & 0.193 & 0.014 & 0.250 & 0.031 & 1.719 \\
\hline 0.30 & 0.126 & 0.158 & 0.101 & 0.214 & 0.214 & 0.019 & 0.277 & 0.042 & 1.583 \\
\hline 0.35 & 0.151 & 0.186 & 0.123 & 0.233 & 0.235 & 0.025 & 0.303 & 0.055 & 1.468 \\
\hline 0.40 & 0.179 & 0.216 & 0.149 & 0.252 & 0.256 & 0.033 & 0.330 & 0.072 & 1.369 \\
\hline 0.45 & 0.210 & 0.250 & 0.179 & 0.272 & 0.279 & 0.043 & 0.358 & 0.092 & 1.279 \\
\hline 0.50 & 0.247 & 0.288 & 0.213 & 0.291 & 0.303 & 0.056 & 0.388 & 0.117 & 1.198 \\
\hline 0.55 & 0.290 & 0.331 & 0.255 & 0.312 & 0.329 & 0.072 & 0.420 & 0.150 & 1.121 \\
\hline 0.60 & 0.341 & 0.383 & 0.306 & 0.335 & 0.357 & 0.094 & 0.456 & 0.192 & 1.048 \\
\hline 0.65 & 0.405 & 0.445 & 0.370 & 0.359 & 0.390 & 0.124 & 0.497 & 0.249 & 0.977 \\
\hline 0.70 & 0.485 & 0.522 & 0.453 & 0.386 & 0.428 & 0.166 & 0.544 & 0.329 & 0.906 \\
\hline 0.75 & 0.593 & 0.623 & 0.566 & 0.418 & 0.475 & 0.230 & 0.602 & 0.446 & 0.834 \\
\hline 0.80 & 0.746 & 0.763 & 0.731 & 0.456 & 0.535 & 0.333 & 0.675 & 0.633 & 0.759 \\
\hline 0.85 & 0.985 & 0.974 & 0.997 & 0.503 & 0.617 & 0.521 & 0.775 & 0.968 & 0.677 \\
\hline 0.90 & 1.425 & 1.349 & 1.503 & 0.567 & 0.746 & 0.946 & 0.933 & 1.499 & 0.581 \\
\hline 0.95 & 2.586 & 2.283 & 2.920 & 0.665 & 0.894 & 2.477 & 1.257 & 2.216 & 0.455 \\
\hline 0.97 & 3.951 & 3.318 & 4.682 & 0.762 & 1.011 & 4.914 & 1.554 & 4.049 & 0.382 \\
\hline
\end{tabular}

Table 2 The CI Value of the Different Molar Ratios of SAL/DTX in MCF-7-MS

\begin{tabular}{|c|c|c|c|c|c|c|c|c|c|}
\hline \multirow[t]{2}{*}{$\mathbf{F a}$} & \multicolumn{9}{|l|}{ S/D } \\
\hline & $9 / 1$ & $6 / 1$ & $3 / 1$ & $2 / I$ & $\mathrm{I} / \mathrm{I}$ & $1 / 2$ & $1 / 3$ & $1 / 6$ & $1 / 9$ \\
\hline 0.05 & 0.041 & 0.045 & 0.010 & 0.086 & 0.112 & 0.172 & 1.330 & 1.698 & 2.650 \\
\hline 0.10 & 0.056 & 0.060 & 0.015 & 0.103 & 0.145 & 0.205 & 1.106 & 1.169 & 2.212 \\
\hline 0.15 & 0.092 & 0.096 & 0.028 & 0.136 & 0.179 & 0.271 & 0.854 & 0.693 & 1.724 \\
\hline 0.20 & 0.131 & 0.131 & 0.042 & 0.162 & 0.203 & 0.325 & 0.728 & 0.502 & 1.479 \\
\hline 0.25 & 0.171 & 0.166 & 0.057 & 0.186 & 0.234 & 0.372 & 0.646 & 0.394 & 1.318 \\
\hline 0.30 & 0.213 & 0.202 & 0.074 & 0.208 & 0.263 & 0.417 & 0.585 & 0.322 & 1.199 \\
\hline 0.35 & 0.260 & $0.24 I$ & 0.092 & 0.230 & 0.292 & 0.460 & 0.536 & 0.270 & 1.104 \\
\hline 0.40 & 0.311 & 0.282 & 0.113 & 0.252 & 0.321 & 0.504 & 0.496 & 0.231 & 1.024 \\
\hline 0.45 & 0.368 & 0.328 & 0.136 & 0.274 & 0.350 & 0.549 & 0.460 & 0.199 & 0.954 \\
\hline 0.50 & 0.433 & 0.378 & 0.164 & 0.298 & 0.381 & 0.595 & 0.429 & 0.172 & 0.892 \\
\hline 0.55 & 0.508 & 0.435 & 0.195 & 0.322 & 0.413 & 0.645 & 0.400 & 0.150 & 0.835 \\
\hline 0.60 & 0.595 & 0.501 & 0.233 & 0.349 & 0.449 & 0.698 & 0.374 & 0.130 & 0.782 \\
\hline 0.65 & 0.701 & 0.579 & 0.280 & 0.379 & 0.488 & 0.758 & 0.348 & 0.113 & 0.731 \\
\hline 0.70 & 0.831 & 0.672 & 0.338 & 0.413 & 0.533 & 0.825 & 0.324 & 0.097 & 0.681 \\
\hline 0.75 & 0.996 & 0.789 & 0.414 & 0.452 & 0.585 & 0.904 & 0.299 & 0.083 & 0.632 \\
\hline 0.80 & 1.217 & 0.942 & 0.518 & 0.500 & 0.649 & 0.999 & 0.274 & 0.070 & 0.582 \\
\hline 0.85 & 1.530 & 1.153 & 0.669 & 0.560 & 0.730 & 1.121 & 0.248 & 0.057 & 0.529 \\
\hline 0.90 & 2.020 & 1.473 & 0.911 & 0.644 & 0.843 & 1.288 & 0.220 & 0.045 & 0.472 \\
\hline 0.95 & 2.922 & 2.040 & 1.375 & 0.775 & 1.019 & 1.549 & 0.188 & 0.032 & 0.405 \\
\hline 0.97 & 4.302 & $3.45 \mathrm{I}$ & 2.670 & 1.044 & 1.385 & 2.087 & 0.145 & 0.019 & 0.317 \\
\hline
\end{tabular}

In vitro Cellular Uptake of Nanoparticles probe and loaded into the nanoparticles. The cellular uptake To investigate the cellular uptake of nanoparticles in MCF-7 profile of NC was observed by CLSM. Compared to free cells and MCF-7-MS, coumarin-6 was used as a fluorescence coumarin-6, NC showed much-enhanced internalization, 
Table 3 Characterization of Nanoparticles

\begin{tabular}{|l|l|l|l|l|l|}
\hline Nanoparticles & Size (nm) & PDI & Zeta Potential (mV) & EE (\%) S/D & Drug Loading (\%) S/D \\
\hline NP & $135.30 \pm 6.35$ & $0.115 \pm 0.011$ & $-23.9 \pm 0.74$ & & \\
NS & $62.86 \pm 2.47$ & $0.211 \pm 0.034$ & $-28.7 \pm 1.66$ & $56.35 \pm 5.71$ & $4.79 \pm 0.62$ \\
ND & $128.03 \pm 5.88$ & $0.075 \pm 0.007$ & $-24.6 \pm 1.52$ & $84.96 \pm 1.27$ & $5.48 \pm 0.43$ \\
NSD & $73.83 \pm 3.59$ & $0.193 \pm 0.021$ & $-25.7 \pm 2.03$ & $53.28 \pm 8.96 / 82.30 \pm 6.12$ & $4.08 \pm 0.86 / 4.12 \pm 0.71$ \\
\hline
\end{tabular}

reflected by the increasing green fluorescence of coumarin-6 in both MCF-7 cells and MCF-7-MS (Figure 3). The results suggest that nanoparticles could enhance the internalization of drugs in both breast cancer cells and BCSCs.

\section{In vitro Cytotoxicity of Nanoparticles}

The cytotoxicity of NP was evaluated in MCF-7 cells and MCF-7-MS. The results showed that NP had no significant cytotoxicity to both MCF-7 cells and MCF-7-MS at a polymer concentration from 1-666.67 $\mu \mathrm{M}$ (corresponding to the concentration of SAL and DTX used in the cytotoxicity). This was as reflected by the fact that the cell viability exceeded $90 \%$, even at the highest polymer concentration, indicating the safety of the drug delivery system (The data are not shown). In addition, in vitro cytotoxicities of free drugs or drug combinations, and nanoparticles or nanoparticle combinations were evaluated in MCF-7 cells and MCF-7-MS (Figure 4 and Table 4). All drugs showed concentration-dependent cytotoxicities. In MCF-7 cells, the IC50 of SAL + DTX was significantly lower than that of SAL $(p<0.001)$ or DTX ( $p$ $<0.05$ ), and the IC50 of NSD was significantly lower than that of NS $(\mathrm{p}<0.001)$ or ND $(\mathrm{p}<0.05)$. This suggests that combination therapy was superior compared to monotherapy (Figure 4A and C). A similar result was obtained in MCF7-MS, except that the IC50 values of NS and ND were significantly lower than that of SAL $(p<0.05)$ and DTX ( $p$ $<0.05)$, and the IC50 values of NS + ND and NSD were significantly lower than that of SAL + DTX $(p<0.05)$. This suggests that encapsulation of drugs by nanoparticles could enhance the cytotoxicity of free drugs. Also, the IC50 of NSD was significantly lower than that of NS + ND $(p<0.05)$, indicating that nanoparticles for co-delivery showed enhanced cytotoxicity against MCF-7-MS as compared to the combination of the two types of nanoparticles (Figure 4B and D).
A

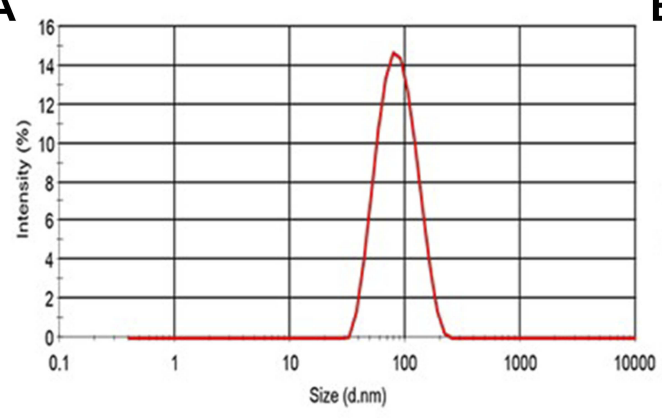

D

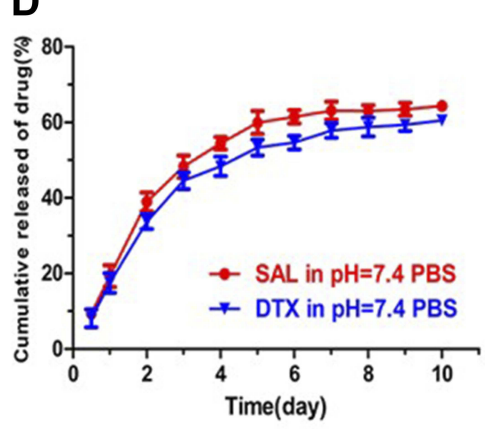

B

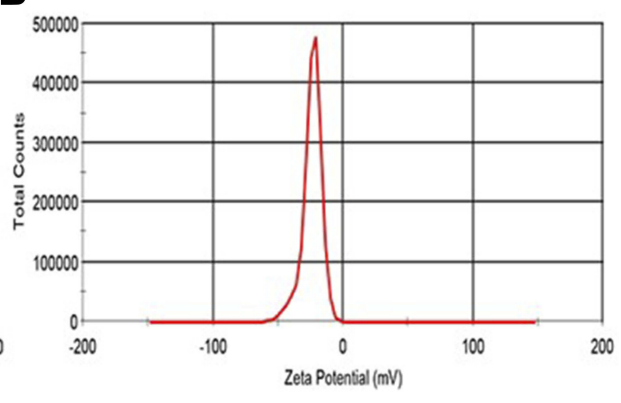

C

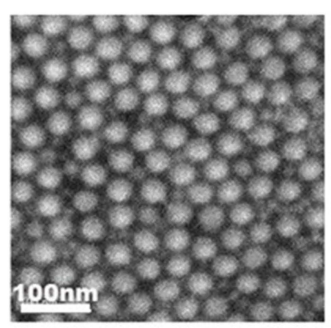

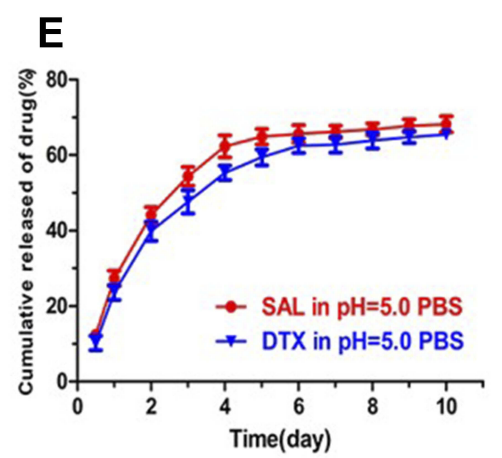

Figure 2 Characterization of nanoparticles. Size distribution (A) and zeta potential of nanoparticles (B), as determined by dynamic light scattering. The TEM image of nanoparticles $(\mathbf{C})$. Bars represent $100 \mathrm{~nm}$. One representative image is shown. The cumulative release of SAL or DTX from nanoparticles at pH 7.4 (D) and 5.0 (E). Data are presented as means \pm standard deviations $(n=3)$. 
A

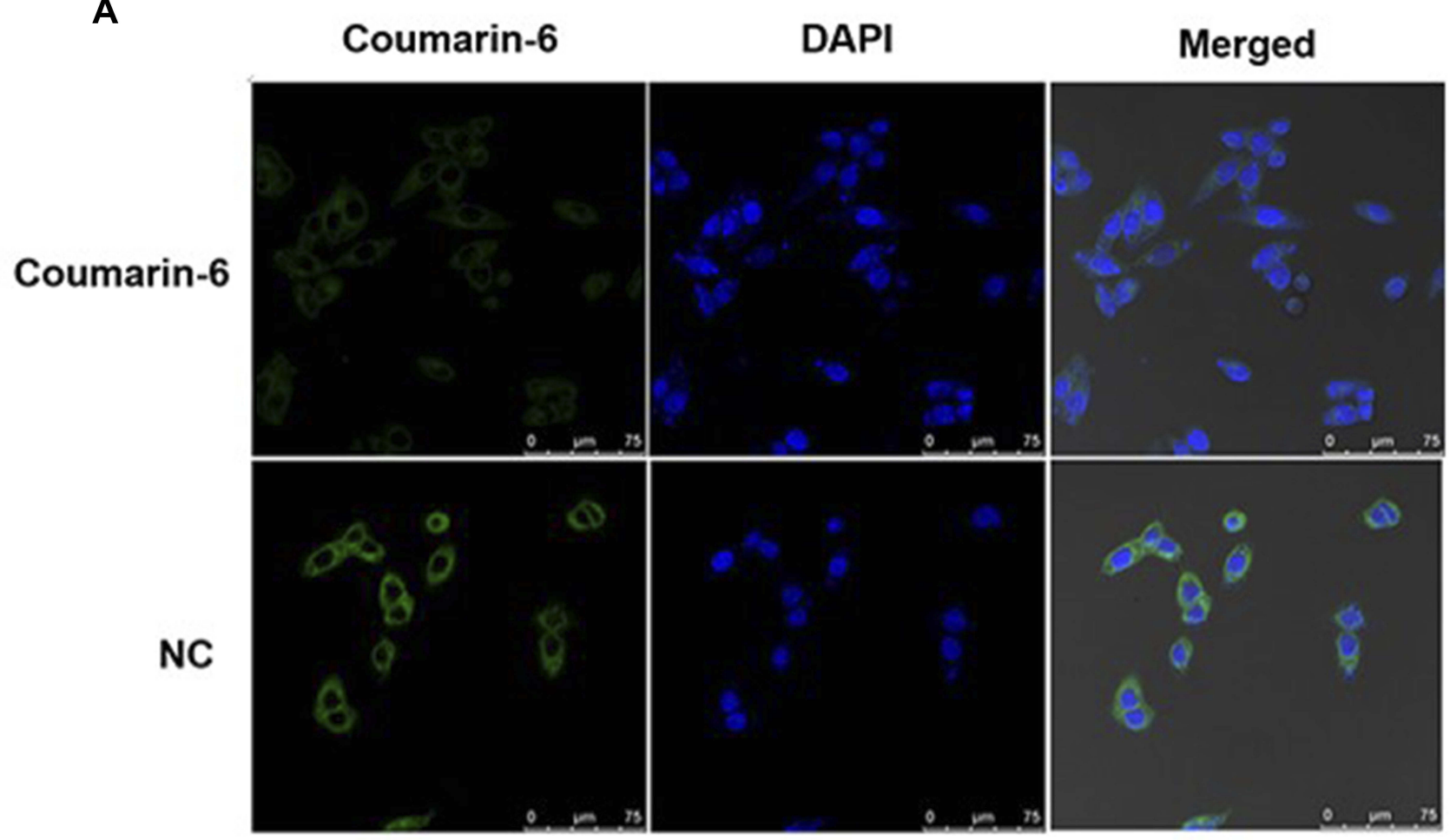

B

Coumarin-6

Coumarin-6
DAPI

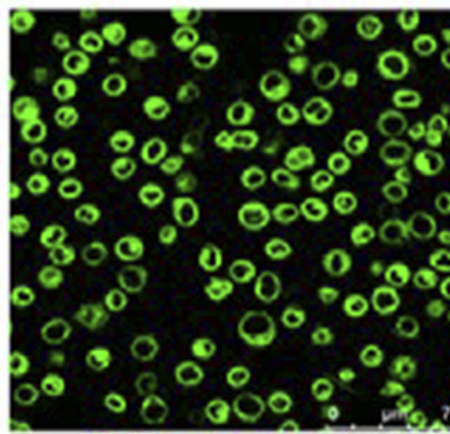

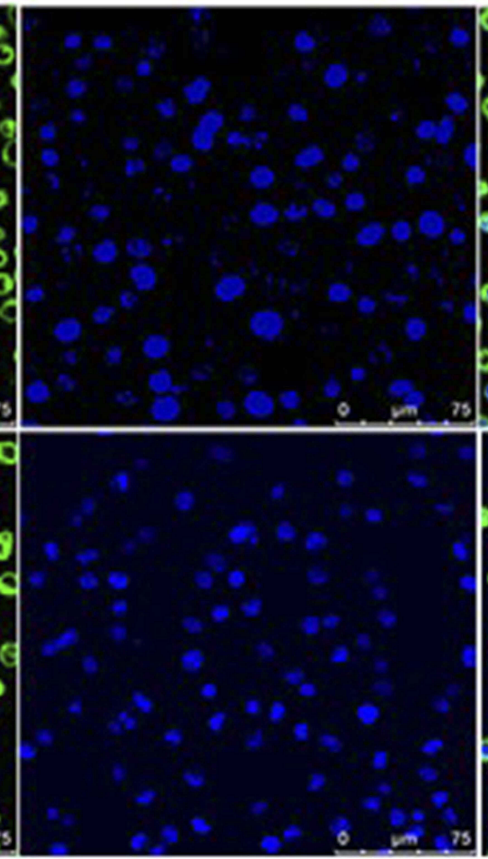

Merged

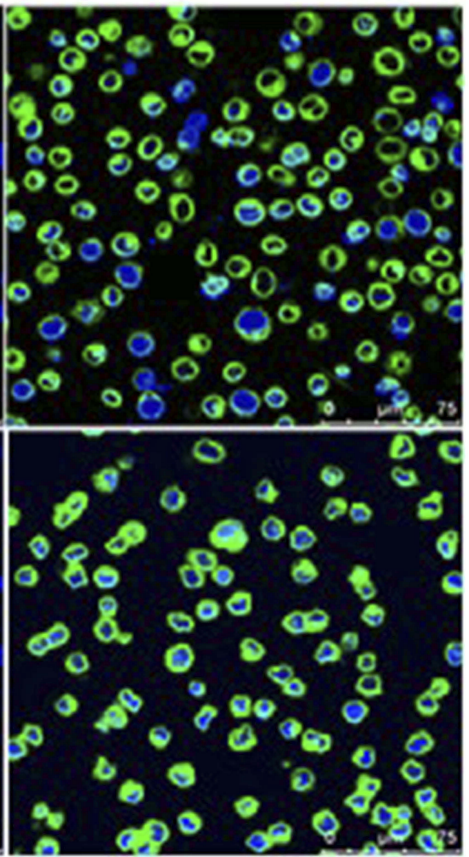

Figure 3 In vitro cellular uptake of nanoparticles. MCF-7 cells (A) and MCF-7-MS (B) were treated with coumarin-6 and NC after I h, followed by staining with DAPI for nuclei. The green fluorescence of coumarin- 6 and blue fluorescence of DAPI were analyzed by a confocal laser scanning microscopy. Bars represent $75 \mu \mathrm{m}$. 
A

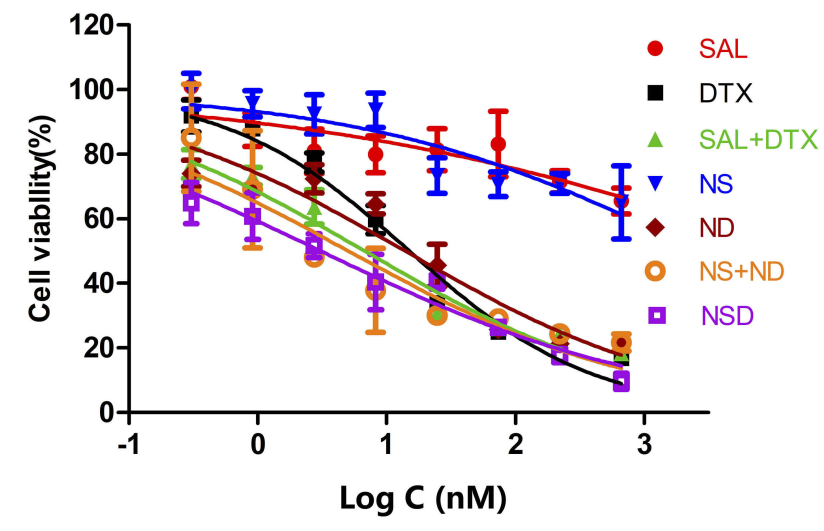

C

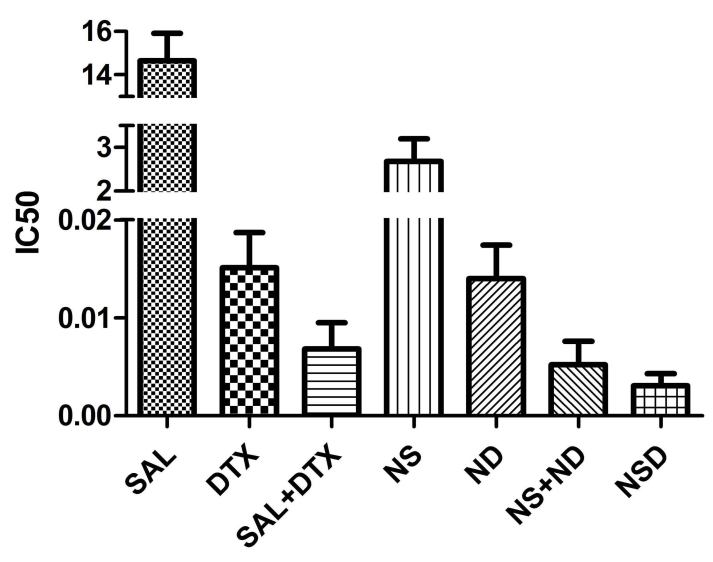

B

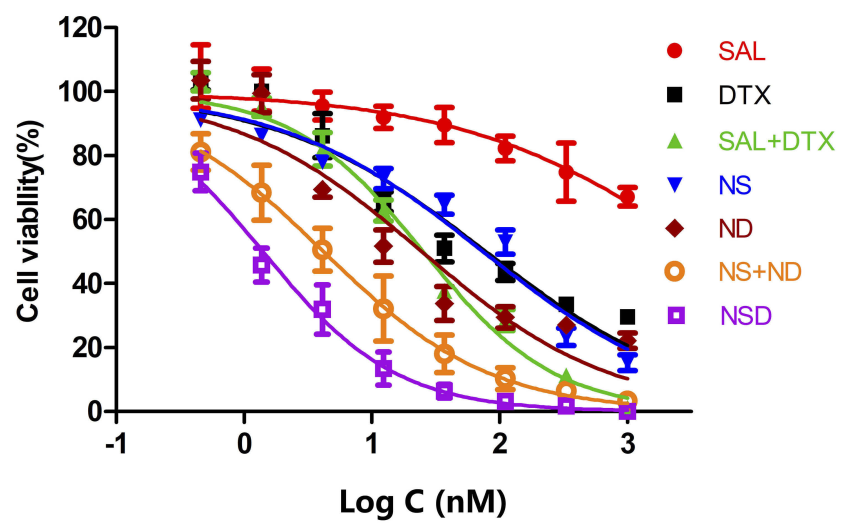

D

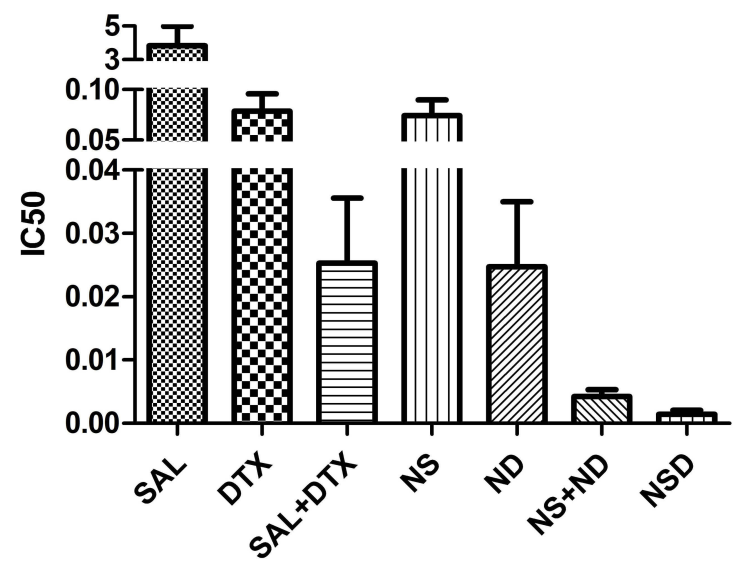

Figure 4 The concentration-dependent cytotoxicity induced by nanoparticles in MCF-7 cells (A, C) or MCF-7-MS (B, D). The cells were incubated for 48 h with varying concentrations of nanoparticles or free SAL or DTX, and the cell viability was evaluated by CCK -8 assays. Data are presented as means \pm standard deviations ( $\mathrm{n}=3$ ).

\section{Pharmacokinetics}

The pharmacokinetic profiles of SAL + DTX, NS +ND, and NSD are shown in Figure 5. The physical pharmacokinetic parameters were calculated using the non-compartment model. In the metabolic process of SAL, plasma half-life

Table 4 IC50 Values of Free Drugs and Drug Loading Nanoparticles Towards MCF-7 Cells and MCF-7-MS at $48 \mathrm{~h}$

\begin{tabular}{|l|l|l|}
\hline Formulations $(\boldsymbol{\mu} M)$ & MCF-7 (S/D) & MCF-7-MS (S/D) \\
\hline SAL & $14.6520 \pm 1.2522$ & $3.8340 \pm 1.1293$ \\
DTX & $0.0151 \pm 0.0036$ & $0.0785 \pm 0.0171$ \\
SAL+DTX & $0.0068 \pm 0.0023 /$ & $0.0253 \pm 0.0103^{\mathrm{c} /}$ \\
NS & $2.6760 \pm 0.5174$ & $0.0745 \pm 0.0152$ \\
ND & $0.0140 \pm 0.0034^{\mathrm{a}}$ & $0.0247 \pm 0.0104$ \\
NS+ND & $0.0052 \pm 0.0024 /$ & $0.0042 \pm 0.001 \mathrm{I} /$ \\
NSD & $0.0031 \pm 0.0012^{\mathrm{b}} /$ & $0.0014 \pm 0.0007^{\mathrm{d}} /$ \\
\hline
\end{tabular}

Notes: The IC50 values between groups was compared by Student's t-test. MCF-7 cells: a ND v.s DTX, $p<0.05$; ${ }^{b} N S D$ v.s ND, $p<0.05$; MCF-7-MS: ' $S A L+D T X$ v.s DTX, $p<0.05 ;{ }^{d} N S+N D$ v.s NSD, $p<0.05(n=3)$. $(\mathrm{t} 1 / 2)$ of SAL in NSD formulation increased by more than 1.2-fold and 2.3-fold compared to NS + ND $(\mathrm{p}<0.05)$ and SAL + DTX $(p<0.01)$, respectively. The clearance $(C L)$ of NSD and NS + ND was significantly less than that of SAL + DTX $(\mathrm{p}<0.01)$. The area under the curve (AUC) for NSD and NS + ND was 2.5-fold and 3.2-fold higher than that of SAL + DTX $(p<0.01)$ respectively (Table 5$)$. Similarly, in the process of DTX metabolism, $\mathrm{t} 1 / 2$ of NSD and NS + ND was significantly more than that of SAL + DTX $(p<0.01)$. The CL of DTX in NSD formulation decreased by more than 1.2-fold and 4.2-fold compared to NS + ND ( $p<0.05)$ and SAL + DTX $(\mathrm{p}<0.01)$, respectively. The AUC for NSD was 1.2-fold and 4.2-fold higher than that of NS + ND ( $<<$ $0.05)$ and SAL + DTX $(p<0.01)$ respectively. The volume of distribution (V) for NSD was 1.2-fold and 2.2-fold less than that of NS + ND $(p<0.05)$ and SAL + DTX $(p<0.01)$ respectively, indicating that DTX showed greater retention in plasma when loaded into PLGA/TPGS nanoparticles (Table 6). These results demonstrated that nanoparticles 

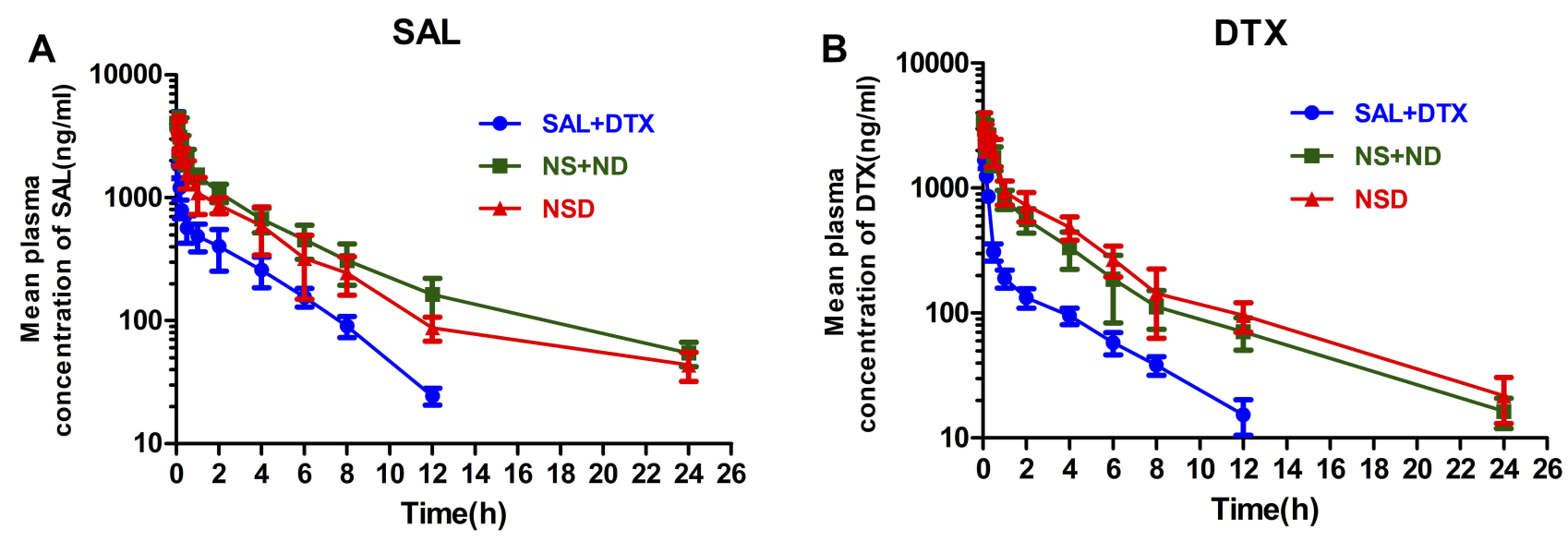

Figure 5 The pharmacokinetic studies after i.v. injection of SAL + DTX, NS + ND and NSD (2 mg/kg SAL and $2.1 \mathrm{mg} / \mathrm{kg} D T X)$ to SD rats via tail vein. Mean plasma concentration versus time of SAL $(\mathbf{A})$ or DTX $(\mathbf{B})$. Data are presented as means \pm standard deviations $(n=5)$.

could prolong circulation time and increase the concentrations of SAL and DTX in vivo.

Next, we examined the changes in the molar ratio of SAL to DTX in vivo over time (Figure 6). The starting mole ratio of SAL to DTX was $1: 1$. We found that the molar ratio of SAL to DTX in NSD could be maintained in the range of $1: 1-2: 1$ within $24 \mathrm{~h}$, in accordance with the synergistic ratio of SAL to DTX determined by in vitro cytotoxicity. However, the ratio of SAL to DTX in SAL + DTX and NS + ND was out of balance. Therefore, NSD can maintain the metabolic ratio of SAL and DTX better than NS + ND. This showed the advantage of NSD as a co-loading formulation to maintain the metabolism of two drugs at a similar rate.

\section{In vivo Tissue Distribution}

To evaluate the tissue distribution of nanoparticles in vivo, the mice bearing subcutaneous MCF-7 tumors were treated with saline, free DiR, and NDiR via the tail vein. The real-time images showed that NDiR could reach and accumulate in the tumor site in a relatively short time (about 2 $\mathrm{h}$ ), and the accumulation increased with an increase in time, reaching the maximum at $24 \mathrm{~h}$. However, no obvious DiR signals were observed in free DiR (Figure 7A). The

Table 5 Pharmacokinetic Parameters of SAL After I.v. Injection of SAL+DTX, NS+ND and NSD at a Dose of $2 \mathrm{mg} / \mathrm{Kg}$

\begin{tabular}{|c|c|c|c|c|}
\hline \multirow[t]{2}{*}{ Parameters } & \multirow[t]{2}{*}{ Unit } & \multicolumn{3}{|l|}{ Formulations } \\
\hline & & SAL+DTX & NS+ND & NSD \\
\hline$t_{1 / 2}$ & $\mathrm{~h}$ & $2.65 I \pm 0.20 I$ & $5.040 \pm 0.427^{\mathrm{b}}$ & $6.311 \pm 0.218^{\mathrm{a}, \mathrm{c}}$ \\
\hline v & $\mathrm{L} / \mathrm{kg}$ & $2.522 \pm 0.789$ & $1.495 \pm 0.484$ & $2.376 \pm 0.660$ \\
\hline $\mathrm{CL}$ & $\mathrm{L} / \mathrm{h} / \mathrm{kg}$ & $0.659 \pm 0.125$ & $0.206 \pm 0.039^{b}$ & $0.261 \pm 0.059^{\mathrm{a}}$ \\
\hline $\mathrm{AUC}_{(0-\infty)}$ & $\mu g / L \cdot h$ & $3033.675 \pm 356.303$ & $9727.474 \pm 1111.997^{b}$ & $7667.683 \pm 1105.618^{a}$ \\
\hline
\end{tabular}

Notes: ${ }^{a} N S D$ v.s SAL+DTX, $p<0.01$; ${ }^{b} N S+N D$ v.s SAL+DTX, $p<0.01$; ${ }^{c} N S D$ v.s NS+ND, $p<0.05(n=5)$.

Abbreviation: $\mathrm{AUC}_{(0-\infty)}$, area under curve.

Table 6 Pharmacokinetic Parameters of DTX After I.v. Injection of SAL+DTX, NS+ND and NSD at a Dose of $2.1 \mathrm{mg} / \mathrm{Kg}$

\begin{tabular}{|l|l|l|l|l|}
\hline \multirow{2}{*}{ Parameters } & Unit & Formulations & NS+ND & NSD \\
\cline { 3 - 5 } & & SAL+DTX & $5.731 \pm 0.135^{\mathrm{b}}$ & $5.804 \pm 0.515^{\mathrm{a}}$ \\
\hline $\mathrm{t}_{\mathrm{l} / 2}$ & $\mathrm{~h}$ & $3.043 \pm 0.074$ & $3.313 \pm 0.736^{\mathrm{b}}$ & $2.709 \pm 0.752^{\mathrm{a}, \mathrm{c}}$ \\
$\mathrm{V}$ & $\mathrm{L} / \mathrm{kg}$ & $6.018 \pm 0.643$ & $0.401 \pm 0.082^{\mathrm{b}}$ & $0.323 \pm 0.067^{\mathrm{a}, \mathrm{c}}$ \\
$\mathrm{CL}$ & $\mathrm{L} / \mathrm{h} / \mathrm{kg}$ & $1.370 \pm 0.175$ & $5241.877 \pm 669.769^{\mathrm{b}}$ & $6493.168 \pm 848.872^{\mathrm{a}, \mathrm{c}}$ \\
$\mathrm{AUC}$ & ug/L-h & $1532.356 \pm 112.478$ & & \\
\hline
\end{tabular}

Notes: ${ }^{a} N S D$ v.s SAL+DTX, $p<0.01 ;{ }^{b} N S+N D$ v.s SAL+DTX, $p<0.01 ;{ }^{c} N S D$ v.s NS+ND, $p>0.05(n=5)$.

Abbreviation: $\mathrm{AUC}_{(0-\infty)}$, area under curve. 


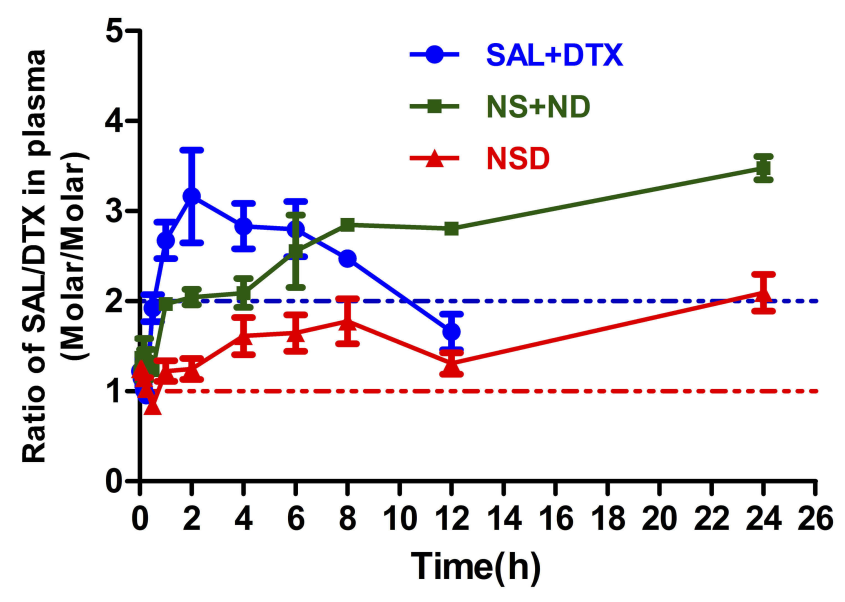

Figure 6 The mole ratio of SAL and DTX in plasma after i.v. injections of SAL + DTX, NS + ND and NSD (2 mg/kg SAL and $2.1 \mathrm{mg} / \mathrm{kg}$ DTX) to SD rats. Data are presented as means \pm standard deviations $(n=5)$.

ex vivo fluorescent images of excised tumors and organs further demonstrated that NDiR mainly accumulated in the liver, the spleen, the lung, the kidney, and the tumor, with most accumulation observed in the tumor, while free DiR mainly accumulated in the liver, the spleen, and the lung, without accumulation observed in the tumor (Figure 7B). Accumulation of nanoparticles in the liver and the spleen may be related to the reticuloendothelial phagocytosis system of the organ. Moreover, nanoparticles have a good sustained-release function and contain TPGS which can inhibit the efflux of P-gp, and reverse tumor multidrug resistance (MDR), thereby increasing the uptake of drugs at the tumor site by the EPR effect. These results indicated that NDiR accumulated more effectively in breast tumors.

\section{In vivo Anti-Tumor Assays}

The anti-tumor efficacy of various formulations was evaluated in mice bearing subcutaneous MCF-7 tumors (Figure 8). First, all formulations, except NP and SAL, significantly reduced the tumor volume compared to saline $(\mathrm{p}<0.05)$, indicating a significant tumor inhibition effect. Notably, NSD showed the best anti-tumor effect compared to all other formulations ( $\mathrm{P}<0.05$, Figure $8 \mathrm{~A}$ and $\mathrm{B}$ ). Next, the tumors were excised and weighed, and the tumor inhibitory rate was calculated at the endpoint, which is consistent with the above data (Figure $8 \mathrm{C}-\mathrm{E}$ ). In addition, the changes in body weights of mice were measured to assess the systemic toxicity of all formulations (Figure 8F). The body weight of DTX and SAL + DTX showed a significant decline trend, indicating that both DTX and SAL had significant toxicity and side effects on the body, while the body weight of other groups did not decrease, suggesting that nanoparticles had good biocompatibility. These results suggested that NSD had significant antitumor activity and minimal systemic toxicity against MCF-7 xenografts.

\section{In vivo Anti-CSCs Activity}

To investigate the anti-CSCs activity in vivo, the population of BCSCs in the excised tumors was measured by mammosphere formation assays (Figure 9). The number and size of the mammosphere in each group containing SAL were smaller than saline $(\mathrm{p}<0.05)$, indicating that SAL could selectively inhibit BCSCs. In contrast, the number of mammospheres increased in DTX and ND while the size reduced. This indicates that DTX can selectively kill normal breast cancer cells, resulting in an increase in the proportion of BCSCs. Notably, the number and size of mammosphere were significantly smaller in NSD and NS + ND than the single nanoparticle and SAL + DTX ( $p<0.05)$, indicating that co-delivery of drugs through nanoparticles is more effective in eradicating BCSCs.

\section{Discussion}

The current interest in cancer research is shifting from monotherapy to combination therapy. Several combination therapies can improve the therapeutic effects of cancer, such as chemo-photothermal therapy, which converts light into heat and improves the efficacy of chemotherapeutic drugs. ${ }^{33,34}$ Our strategy is to combine two chemotherapeutic drugs simultaneously for bulky breast cancer cells and BCSCs, which can maximize the therapeutic efficacy of chemotherapy and minimize the MDR without special laser excitation. ${ }^{10,35-38}$ In this study, we chose DTX and SAL for combination therapy to enhance the therapeutic effect of breast cancer. Our results showed that NSD could prolong the circulation time and maintain the synergistic ratio of SAL to DTX for $24 \mathrm{~h}$ in vivo, exhibiting better tumor targeting, and anti-tumor and CSCs activity than other treatment strategies.

The selection of chemotherapeutics is critically important for the superior activity of our combined therapy. DTX, a first-line chemotherapy drug for breast cancer, can form stable non-functional microtubule bundles by enhancing the polymerization of tubulin and inhibiting the depolymerization of microtubules, thereby disrupting mitosis in tumor cells and arresting cell cycle at G2/M phase. ${ }^{39} \mathrm{SAL}$ is a kind of polyether ionophore antibiotic, which can inhibit and kill most Gram-positive bacteria and 
A

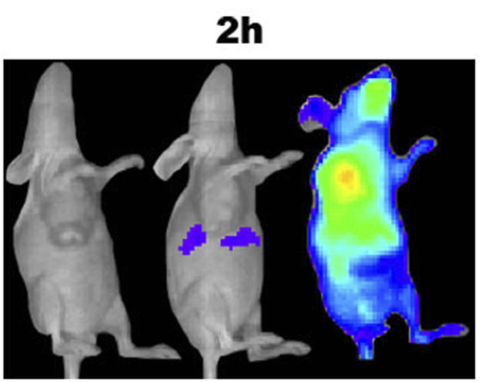

8h

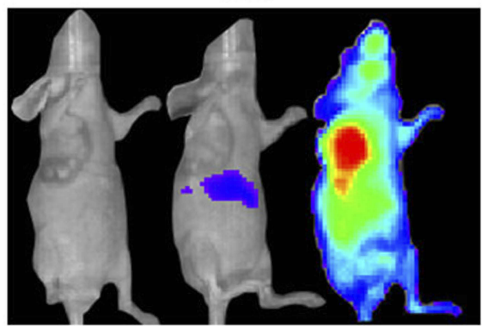

$c^{2 n^{2}} b^{2} \quad 5$ 4h
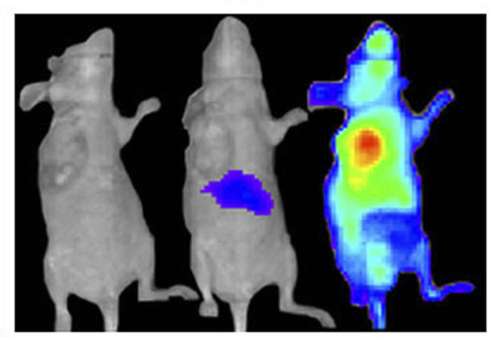

$12 \mathrm{~h}$

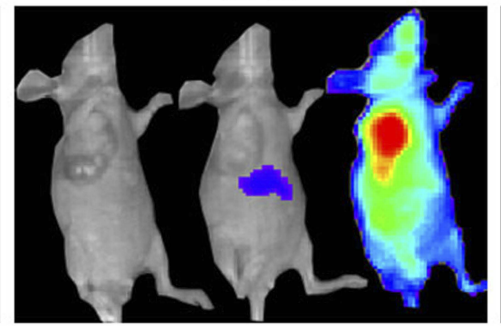

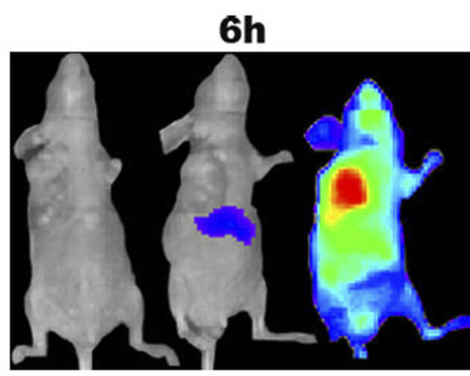

24h

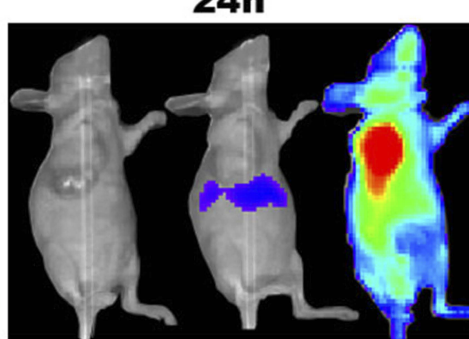
$\times 10^{10}$

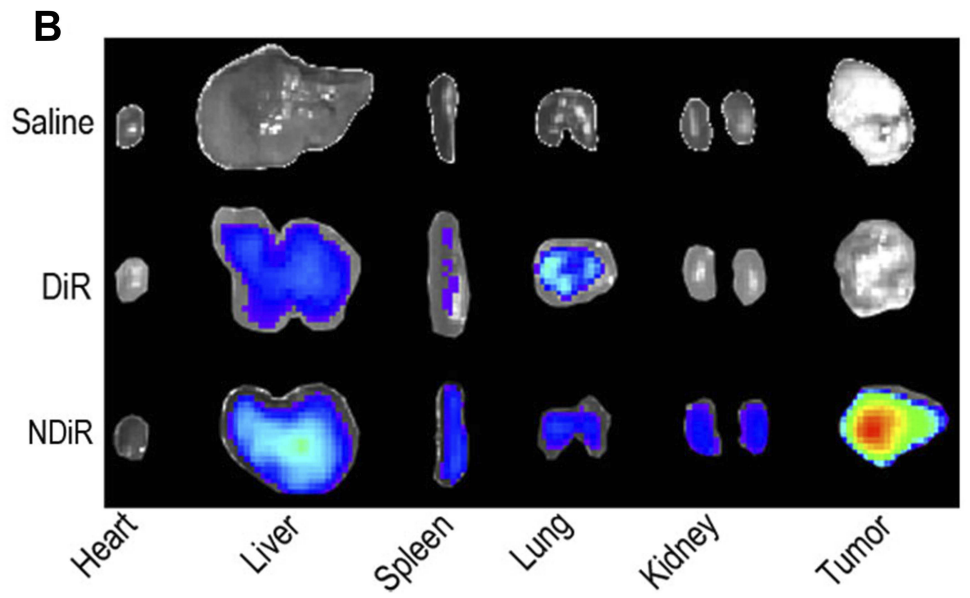

Figure 7 Tissue distribution in vivo. BALB/c nude mice bearing MCF-7 breast cancer-derived tumors were given tail vein injections of saline, free DiR, or NDiR. Timedependent in vivo images of mice after treatment with formulations (A). Ex vivo images of tumors and other organs at $24 \mathrm{~h}$ post-injection of the formulations (B).

coccidiosis. A study published in Cell in 2009 reported that SAL could selectively inhibit BCSCs. ${ }^{40}$ In addition, SAL can increase the sensitivity of tumor cells to chemotherapy drugs by preventing G2 phase arrest and increasing DNA damage. Our previous studies showed that SAL could significantly inhibit the growth of liver CSCs both in vitro and in vivo. ${ }^{41,42}$ Therefore, SAL represents a promising drug against various kinds of CSCs. Thus, in this study, we chose the combination of DTX and SAL, which could target both bulky breast cancer cells and BCSCs as a promising strategy to increase the therapeutic efficacy of breast cancer. However, the combination of multiple drugs could interact synergistically, additively, and even antagonistically, depending on the drug ratio. Therefore, it is crucial to optimize the drug ratio using the median-effect analysis to obtain a synergistic effect. Our previous studies had particularly focused on the ratio of drug combinations, and we obtained a superior therapeutic efficacy. ${ }^{6,43}$ In this study, we rigorously examined the optimal ratio of DTX, and SAL needed for synergism. The CI values of SAL/DTX molar ratio of 2:1 and 1:1 were less than 1 at every drug concentration in MCF-7 cells and at almost all concentrations in MCF-7-MS. Considering the severe toxicity of SAL, we chose SAL/DTX molar ratio of 1:1 as the synergistic ratio. The determination of the synergistic ratio of 

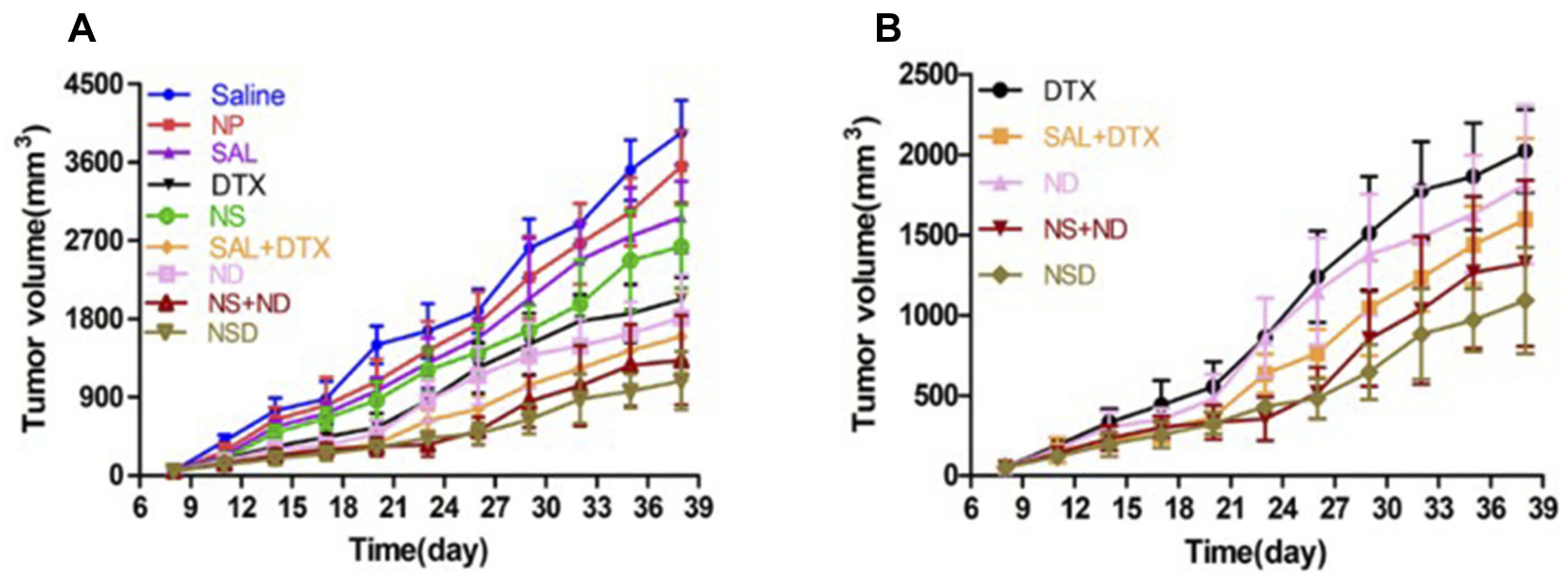

C

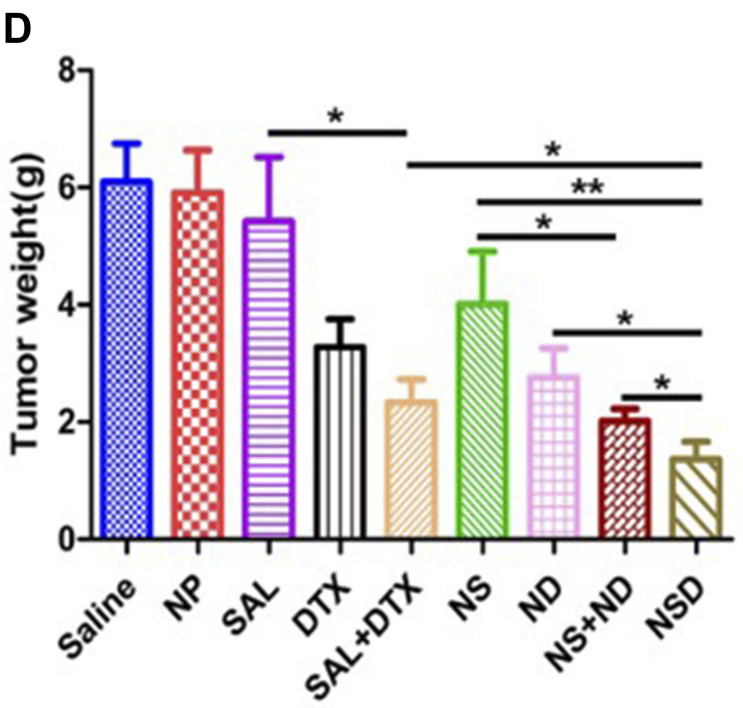

\begin{tabular}{ccc}
\hline E & Tumor & BW $_{1} / \mathrm{BW}_{0}(\%)$ \\
\hline Saline & $/$ & $119.10 \pm 13.74$ \\
NP & $3.11 \pm 4.92$ & $129.57 \pm 7.68$ \\
SAL & $11.15 \pm 13.11$ & $111.50 \pm 9.35$ \\
DTX & $46.23 \pm 7.38$ & $84.98 \pm 10.72$ \\
SAL +DTX & $61.80 \pm 6.56$ & $78.34 \pm 10.06$ \\
NS & $34.26 \pm 14.75$ & $116.39 \pm 10.80$ \\
ND & $54.75 \pm 8.20$ & $108.30 \pm 8.73$ \\
NS+ND & $66.89 \pm 6.56$ & $114.89 \pm 8.05$ \\
NSD & $77.70 \pm 4.92$ & $123.35 \pm 9.45$ \\
\hline
\end{tabular}

Data are represented as mean $\pm \mathrm{SD}(\mathrm{n}=6)$

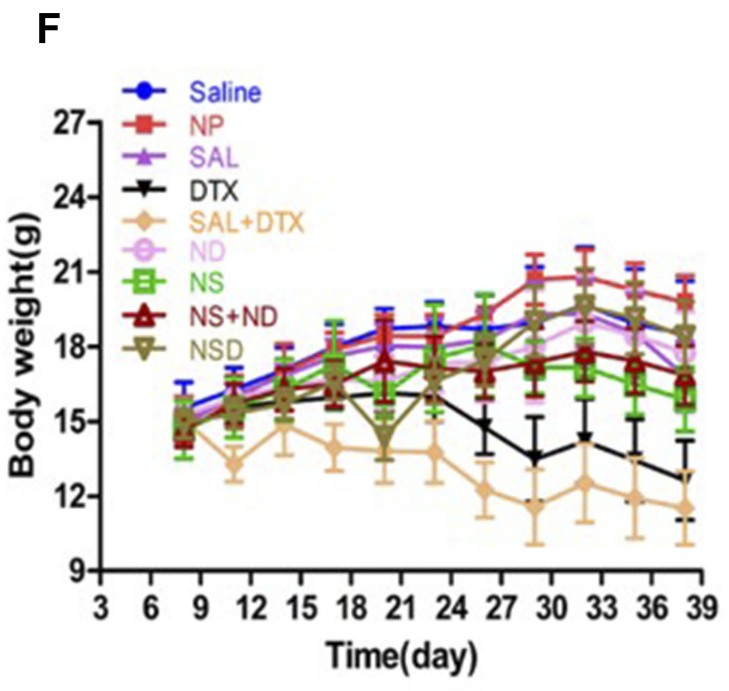

Figure 8 Therapeutic effects of nanoparticles in mice bearing subcutaneous MCF-7 tumors. Mice were treated with intravenous injections of the nanoparticles or free drugs (SAL $2 \mathrm{mg} / \mathrm{kg}$; DTX $2.1 \mathrm{mg} / \mathrm{kg}$ ) via the tail vein. Tumor growth curves $(\mathbf{A})$. The enlarged profiles of DTX, SAL + DTX, ND, NS + ND and NSD on the growth of tumors (B). Images of excised tumors in each group at the endpoint $(\mathbf{C})$. The excised tumors were weighed at the endpoint $(\mathbf{D})$. $*_{\mathrm{p}}<0.05$; ** $\mathrm{p}<0.01$. Body weight change rate and tumor inhibitory rate after treatment of different formulations $(\mathbf{E})$. Weight changes in mice during the treatment $(\mathbf{F})$. Data are presented as means \pm standard deviations $(n=6)$. 
A

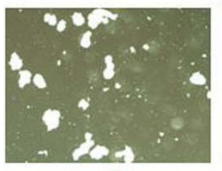

Saline

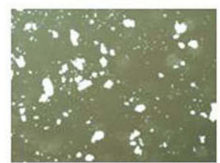

ND

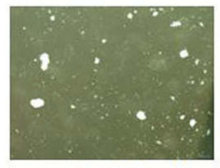

SAL+DTX

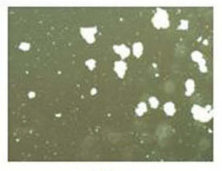

NP

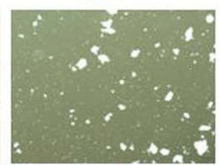

SAL

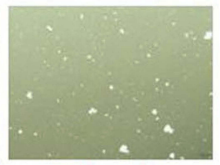

NS+ND

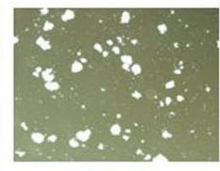

DTX

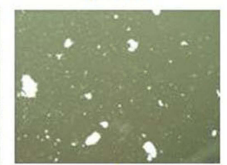

NS

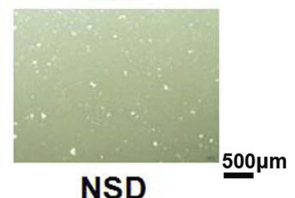

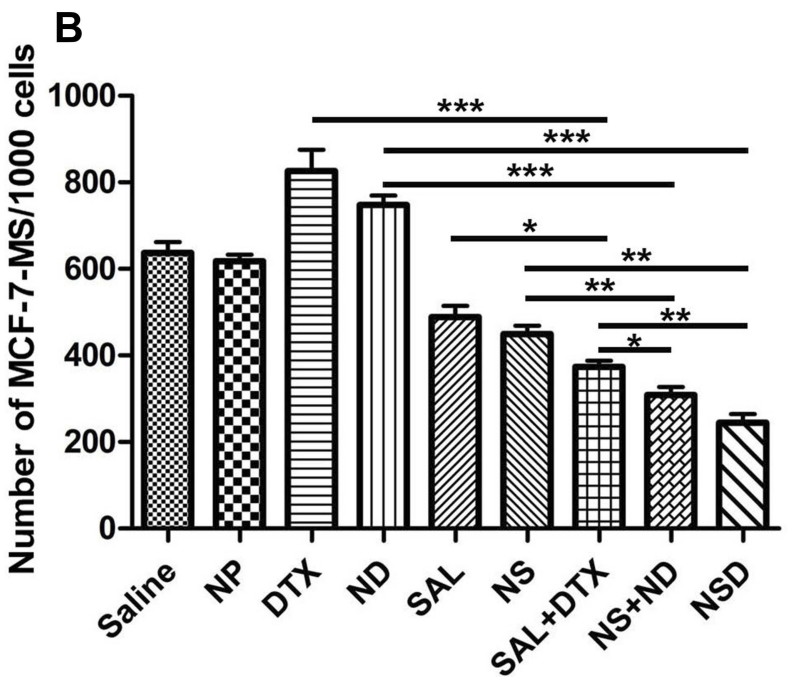

Figure 9 In vivo anti-CSCs activity. Image of tumorspheres of excised tumors (A). Tumorsphere-forming efficiency of excised tumor cells (B). Data are presented as means \pm standard deviations $(\mathrm{n}=3) .{ }^{*} \mathrm{p}<0.05 ;{ }^{* *} \mathrm{p}<0.01$; **** $\mathrm{p}<0.001$.

DTX and SAL was important for their performance of synergistic effects.

At present, the combination therapy in the clinic is mainly based on the co-administration of conventional dosage forms, but the outcome is still unsatisfactory due to poor water solubility and bioavailability, short elimination halflife, the difference in pharmacokinetics and bio-distribution of chemotherapeutic drugs, etc. More importantly, the synergistic ratio of drugs is difficult to maintain and thus the therapeutic efficacy of the combined therapy is hard to predict. How to overcome the different pharmacokinetic characteristics of multiple drugs and deliver them simultaneously to the tumor site in a synergistic ratio will be the key to combined chemotherapy. Nanomedicines could provide a new idea for solving the problem of a drug combination strategy. ${ }^{44,45}$ Currently, there are usually two approaches for combination therapy based on nanomedicines: the coadministration of two single drug-loaded delivery systems and the co-delivery of two drugs in a single delivery system. The use of two individual nanomedicines can be flexibly administered at different doses and times, but it is difficult to achieve synchronizing pharmacokinetics and biodistribution to maintain the synergistic ratio of drugs in the tumor sites. In contrast, co-delivery in nanomedicine can unify the pharmacokinetics of co-encapsulated drugs, which are of great significance in achieving the synergistic effect. $^{46}$ In our previous study, we have demonstrated that simultaneously co-delivering of two drugs to the tumor via a single nanoliposome could better maintain the synergistic drug ratio in vivo than the co-administration of two single drugs and drug-loaded nanoliposomes. However, the poor ability of nanoliposomes to maintain the synergistic drug ratio should be improved. ${ }^{6}$ In this study, we developed the PLGA/TPGS nanoparticle for co-delivering of DTX and SAL to improve the ability to maintain synergistic drug ratios. The data presented here confirmed that NSD was efficiently bound and delivered to both breast cancer cells and BCSCs. Upon cell binding, NSD was readily internalized and it released drugs to the cytoplasm, resulting in enhanced growth-inhibitory effect compared to single-drug treatment, and a combination of two nanoparticles. This suggests that co-delivery of drugs through nanoparticles may better exert synergistic effect than the combination of two distinct nanoparticles. The tissue distribution further demonstrated significant uptake of DiR loaded nanoparticles in breast cancer in vivo. The in vivo results showed that the molar ratio of SAL to DTX in NSD could be maintained in the range of $1: 1-2: 1$ within $24 \mathrm{~h}$. Compared to nanoliposomes which we had reported in previous study, the fluctuation of drug ratio reduced, and the time of maintaining the synergistic drug ratio was prolonged significantly. Consistently, NSD showed the best anti-tumor and antiCSCs activity, and minimal systemic toxicity against MCF7 xenografts. Summarily, we have demonstrated for the first time that nanoparticles for co-delivery of a conventional chemotherapy drug and an anti-CSCs drug could maintain a synergistic ratio for $24 \mathrm{~h}$ in vivo and showed superior therapeutic efficacy towards both breast cancer cells and CSCs. 
The nanoparticles we developed could be considered as another strength. Poly lactic-co-glycolic acid (PLGA) is a kind of biodegradable organic polymer polymerized by lactic acid and glycolic acid monomers. The degradation products of PLGA are lactic acid and glycolic acid, which are also by-products of the metabolic pathway in human body. Therefore, PLGA has good biocompatibility, biodegradability, and modifiability, and it is widely used as carrier material for tumor targeting delivery systems.$^{20}$ However, it requires a long degradation time in vivo due to its compaction structure. Therefore, various strategies such as surface modification, newly synthesized and porous have been developed to improve the PLGA nanoparticles. ${ }^{30,47,48}$ In recent years, many studies have found that TPGS has many unique characteristics, such as absorption enhancer, mucosal immune adjuvant, and multi-drug resistance reversal property. TPGS can also be used as precursor drugs, micelles, and liposomes to improve the solubility, permeability, and stability of the preparation; thus, achieving sustained, controlled release and targeting effects. ${ }^{27,49}$ In this study, we used TPGS as a pore-forming agent to improve the performance of PLGA nanoparticles. The advantages of PLGA/TPGS nanoparticles are that both PLGA and TPGS are FDA-approved materials with good biocompatibility. In addition, unlike PLGA-PEG nanoparticles, PLGA/TPGS nanoparticles do not require the synthesis of new compounds and can be physically mixed directly. Therefore, they have good prospects for expanding production in the future.

\section{Conclusion}

In this study, PLGA/TPGS nanoparticles were prepared by co-encapsulating DTX and SAL. This allowed the simultaneous delivery of the two drugs at a synergistic ratio to the tumor site and to target both breast cancer cells and BCSCs. The results obtained from both in vitro and in vivo studies demonstrated that co-delivery of DTX and SAL in a single PLGA/TPGS nanoparticle could effectively inhibit the proliferation of breast cancer cells and BCSCs. This indicates that this is a promising strategy for breast cancer treatment. To the best of our knowledge, this is the first-time nanoparticles were constructed for codelivery of conventional chemotherapy and anti-CSCs drugs, which could maintain a synergistic ratio for 24 $\mathrm{h}$ in vivo to eliminate both cancer cells and CSCs. Our study presents the possibility of using nanoparticles for codelivery of chemotherapy and anti-CSCs drugs in a synergistic ratio to target cancer cells and CSCs.

\section{Acknowledgment}

This work was supported by the National Natural Science Foundation of China (Grant No. 81573376, 81803450).

\section{Disclosure}

The authors report no conflicts of interest in this work.

\section{References}

1. Siegel RL, Miller KD, Jemal A. Cancer statistics, 2019. CA Cancer J Clin. 2019;69(1):7-34. doi:10.3322/caac.21551

2. Chaffer CL, Brueckmann I, Scheel C, et al. Normal and neoplastic nonstem cells can spontaneously convert to a stemlike state. Proc Natl Acad Sci U S A. 2011;108(19):7950-7955. doi:10.1073/pnas.1102454108

3. Gupta PB, Fillmore CM, Jiang G, et al. Stochastic state transitions give rise to phenotypic equilibrium in populations of cancer cells. Cell. 2011;146(4):633-644. doi:10.1016/j.cell.2011.07.026

4. Iliopoulos D, Hirsch HA, Wang G, et al. Inducible formation of breast cancer stem cells and their dynamic equilibrium with non-stem cancer cells via IL6 secretion. Proc Natl Acad Sci U S A. 2011;108(4):1397-1402. doi:10.1073/pnas.1018898108

5. Meacham CE, Morrison SJ. Tumour heterogeneity and cancer cell plasticity. Nature. 2013;501(7467):328-337. doi:10.1038/nature12624

6. Gong Z, Chen D, Xie F, et al. Codelivery of salinomycin and doxorubicin using nanoliposomes for targeting both liver cancer cells and cancer stem cells. Nanomedicine (Lond). 2016;11 (19):2565-2579. doi:10.2217/nnm-2016-0137

7. Al-Hajj M, Wicha MS, Benito-Hernandez A, et al. Prospective identification of tumorigenic breast cancer cells. Proc Natl Acad Sci U S A. 2003;100(7):3983-3988. doi:10.1073/pnas.0530291100

8. Abbaszadegan MR, Bagheri V, Razavi MS, et al. Isolation, identification, and characterization of cancer stem cells: A review. J Cell Physiol. 2017;232(8):2008-2018. doi:10.1002/jcp.v232.8

9. Ponti D, Costa A, Zaffaroni N, et al. Isolation and in vitro propagation of tumorigenic breast cancer cells with stem/progenitor cell properties. Cancer Res. 2005;65(13):5506-5511. doi:10.1158/00085472.CAN-05-0626

10. Wang D, Huang J, Wang X, et al. The eradication of breast cancer cells and stem cells by 8 -hydroxyquinoline-loaded hyaluronan modified mesoporous silica nanoparticle-supported lipid bilayers containing docetaxel. Biomaterials. 2013;34(31):7662-7673. doi:10.1016/j. biomaterials.2013.06.042

11. Dubrovska A, Elliott J, Salamone RJ, et al. Combination therapy targeting both tumor-initiating and differentiated cell populations in prostate carcinoma. Clin Cancer Res. 2010;16(23):5692-5702. doi:10.1158/1078-0432.CCR-10-1601

12. Mueller MT, Hermann PC, Witthauer J, et al. Combined targeted treatment to eliminate tumorigenic cancer stem cells in human pancreatic cancer. Gastroenterology. 2009;137(3):1102-1113. doi:10.1053/j. gastro.2009.05.053

13. Shi J, Kantoff PW, Wooster R, et al. Cancer nanomedicine: progress, challenges and opportunities. Nat Rev Cancer. 2017;17(1):20-37. doi:10.1038/nrc.2016.108

14. Beik J, Khateri M, Khosravi Z, et al. Gold nanoparticles in combinatorial cancer therapy strategies. Coord Chem Rev. 2019;387:299-324. doi:10.1016/j.ccr.2019.02.025

15. Beik J, Khademi S, Attaran N, et al. A Nanotechnology-based strategy to increase the efficiency of cancer diagnosis and therapy: folate-conjugated gold nanoparticles. Curr Med Chem. 2017;24 (39):4399-4416. doi:10.2174/0929867324666170810154917

16. Zhang RX, Wong HL, Xue HY, et al. Nanomedicine of synergistic drug combinations for cancer therapy - Strategies and perspectives. J Control Release. 2016;240:489-503. doi:10.1016/j.jconrel.2016.06.012 
17. Liboiron BD, Mayer LD. Nanoscale particulate systems for multidrug delivery: towards improved combination chemotherapy. Ther Deliv. 2014;5(2):149-171. doi:10.4155/tde.13.149

18. Dicko A, Mayer LD, Tardi PG. Use of nanoscale delivery systems to maintain synergistic drug ratios in vivo. Expert Opin Drug Deliv. 2010;7(12):1329-1341. doi:10.1517/17425247.2010.538678

19. Danhier F, Ansorena E, Silva JM, et al. PLGA-based nanoparticles: an overview of biomedical applications. J Control Release. 2012;161 (2):505-522. doi:10.1016/j.jconrel.2012.01.043

20. Mir M, Ahmed N, Rehman AU. Recent applications of PLGA based nanostructures in drug delivery. Colloids Surf B Biointerfaces. 2017;159:217-231. doi:10.1016/j.colsurfb.2017.07.038

21. Kapoor DN, Bhatia A, Kaur R, et al. PLGA: a unique polymer for drug delivery. Ther Deliv. 2015;6(1):41-58. doi:10.4155/tde.14.91

22. Shakeri-Zadeh A, Shiran MB, Khoee S, et al. A new magnetic nanocapsule containing 5-fluorouracil: in vivo drug release, anti-tumor, and pro-apoptotic effects on CT26 cells allograft model. J Biomater Appl. 2014;29(4):548-556. doi:10.1177/0885328214536940

23. Shakeri-Zadeh A, Khoei S, Khoee S, et al. Combination of ultrasound and newly synthesized magnetic nanocapsules affects the temperature profile of CT26 tumors in BALB/c mice. J Med Ultrason. 2015;42 (1):9-16. doi:10.1007/s10396-014-0558-4

24. Chen H, Xie LQ, Qin J, et al. Surface modification of PLGA nanoparticles with biotinylated chitosan for the sustained in vitro release and the enhanced cytotoxicity of epirubicin. Colloids Surf B Biointerfaces. 2016;138:1-9. doi:10.1016/j.colsurfb.2015.11.033

25. Wang Y, Liu X, Liu G, et al. Novel galactosylated biodegradable nanoparticles for hepatocyte-delivery of oridonin. Int J Pharm. 2016;502(1-2):47-60. doi:10.1016/j.ijpharm.2016.02.025

26. Tang X, Liang Y, Feng X, et al. Co-delivery of docetaxel and Poloxamer 235 by PLGA-TPGS nanoparticles for breast cancer treatment. Mater Sci Eng C Mater Biol Appl. 2015;49:348-355. doi:10.1016/j.msec.2015.01.033

27. Tan S, Zou C, Zhang W, et al. Recent developments in d- $\alpha$-tocopheryl polyethylene glycol-succinate-based nanomedicine for cancer therapy. Drug Deliv. 2017;24(1):1831-1842. doi:10.1080/10717544.2017. 1406561

28. Guo Y, Luo J, Tan S, et al. The applications of Vitamin E TPGS in drug delivery. Eur J Pharm Sci. 2016;49(2):175-186. doi:10.1016/j. ejps.2013.02.006

29. Zhang Z, Tan S, Feng -S-S. Vitamin E TPGS as a molecular biomaterial for drug delivery. Biomaterials. 2012;33(19):4889-4906. doi:10.1016/j.biomaterials.2012.03.046

30. Zhu H, Chen H, Zeng X, et al. Co-delivery of chemotherapeutic drugs with vitamin E TPGS by porous PLGA nanoparticles for enhanced chemotherapy against multi-drug resistance. Biomaterials. 2014;35(7):2391-2400. doi:10.1016/j.biomaterials.2013.11.086

31. Chen D, Pan X, Xie F, et al. Codelivery of doxorubicin and elacridar to target both liver cancer cells and stem cells by polylactide-coglycolide/d-alpha-tocopherol polyethylene glycol 1000 succinate nanoparticles. Int J Nanomed. 2018;13:6855-6870. doi:10.2147/IJN. S181928

32. Chou TC, Talalay P. Quantitative analysis of dose-effect relationships: the combined effects of multiple drugs or enzyme inhibitors. Adv Enzyme Regul. 1984;22:27-55. doi:10.1016/0065-2571(84)90007-4

33. Mirrahimi M, Abed Z, Beik J, et al. A thermo-responsive alginate nanogel platform co-loaded with gold nanoparticles and cisplatin for combined cancer chemo-photothermal therapy. Pharmacol Res. 2019;143:178-185. doi:10.1016/j.phrs.2019.01.005
34. Alamzadeh Z, Beik J, Pirhajati Mahabadi V, et al. Ultrastructural and optical characteristics of cancer cells treated by a nanotechnology based chemo-photothermal therapy method. J Photochem Photobiol B. 2019;192:19-25. doi:10.1016/j.jphotobiol.2019.01.005

35. Huang J, Tao C, Yu Y, et al. Simultaneous targeting of differentiated breast cancer cells and breast cancer stem cells by combination of docetaxel- and sulforaphane-Loaded self-assembled poly(D, L-lactide-co-glycolide) /hyaluronic acid block copolymer-based nanoparticles. J Biomed Nanotechnol. 2016;12(7):1463-1477. doi:10.1166/jbn.2016.2234

36. Kim YJ, Liu Y, Li S, et al. Co-eradication of breast cancer cells and cancer stem cells by cross-linked multilamellar liposomes enhances tumor treatment. Mol Pharm. 2015;12(8):2811-2822. doi:10.1021/ $\mathrm{mp} 500754 \mathrm{r}$

37. Ke XY, Ng VW L, Gao SJ, et al. Co-delivery of thioridazine and doxorubicin using polymeric micelles for targeting both cancer cells and cancer stem cells. Biomaterials. 2014;35(3):1096-1108. doi:10.1016/j.biomaterials.2013.10.049

38. Zhang Y, Zhang H, Wang X, et al. The eradication of breast cancer and cancer stem cells using octreotide modified paclitaxel active targeting micelles and salinomycin passive targeting micelles. Biomaterials. 2012;33(2):679-691. doi:10.1016/j.biomaterials.2011.09.072

39. Zhang S, Guan J, Sun M, et al. Self-delivering prodrug-nanoassemblies fabricated by disulfide bond bridged oleate prodrug of docetaxel for breast cancer therapy. Drug Deliv. 2017;24(1):1460-1469. doi:10.1080/ 10717544.2017.1381201

40. Gupta PB, Onder TT, Jiang G, et al. Identification of selective inhibitors of cancer stem cells by high-throughput screening. Cell. 2009;138(4):645-659. doi:10.1016/j.cell.2009.06.034

41. Mao X, Liu J, Gong Z, et al. iRGD-conjugated DSPE-PEG2000 nanomicelles for targeted delivery of salinomycin for treatment of both liver cancer cells and cancer stem cells. Nanomedicine (Lond). 2015;10(17):2677-2695. doi:10.2217/nnm.15.106

42. Wang M, Xie F, Wen X, et al. Therapeutic PEG-ceramide nanomicelles synergize with salinomycin to target both liver cancer cells and cancer stem cells. Nanomedicine (Lond). 2017;12(9):1025-1042.3. doi:10.2217/nnm-2016-0408

43. Xie F, Zhang S, Liu J, et al. Codelivery of salinomycin and chloroquine by liposomes enables synergistic antitumor activity in vitro. Nanomedicine (Lond). 2016;11(14):1831-1846. doi:10.2217/nnm-2016-0125

44. Ma L, Kohli M, Smith A. Nanoparticles for combination drug therapy. ACS Nano. 2013;7:9518-9525. doi:10.1021/nn405674m

45. Piccolo MT, Menale C, Crispi S. Combined anticancer therapies: an overview of the latest applications. Anti Cancer Agents Med Chem. 2015;15:408-422. doi:10.2174/1871520615666150113123039

46. Dai W, Wang X, Song G, et al. Combination antitumor therapy with targeted dual-nanomedicines. Adv Drug Deliv Rev. 2017;115:23-45. doi:10.1016/j.addr.2017.03.001

47. Dong $\mathrm{H}, \mathrm{Wu} \mathrm{G}, \mathrm{Xu} \mathrm{H}$, et al. N-acetylaminogalactosyl-decorated biodegradable PLGA-TPGS copolymer nanoparticles containing emodin for the active targeting therapy of liver cancer. Artif Cells Nanomed Biotechnol. 2018;46(sup2):260-272. doi:10.1080/21691401.2018. 1455055

48. Shafiei-Irannejad V, Samadi N, Salehi R, et al. Reversion of multidrug resistance by co-encapsulation of doxorubicin and metformin in Poly(lactide-co-glycolide)-d- $\alpha$-tocopheryl polyethylene glycol 1000 succinate nanoparticles. Pharm Res. 2018;35(6):119. doi:10.1007/ s11095-018-2404-7

49. Yang C, Wu T, Qi Y, et al. Recent advances in the application of vitamin E TPGS for drug delivery. Theranostics. 2018;8(2):464-485. doi:10.7150/thno. 22711 


\section{Publish your work in this journal}

The International Journal of Nanomedicine is an international, peerreviewed journal focusing on the application of nanotechnology in diagnostics, therapeutics, and drug delivery systems throughout the biomedical field. This journal is indexed on PubMed Central, MedLine, CAS, SciSearch ${ }^{\mathbb{B}}$, Current Contents ${ }^{\mathbb{B}} /$ Clinical Medicine,

Journal Citation Reports/Science Edition, EMBase, Scopus and the Elsevier Bibliographic databases. The manuscript management system is completely online and includes a very quick and fair peer-review system, which is all easy to use. Visit http://www.dovepress.com/ testimonials.php to read real quotes from published authors. 